\title{
Flexible water allocations and rotational delivery combined adapt irrigation systems to drought
}

\author{
Kelsey C. Cody ${ }^{1}$
}

\begin{abstract}
Self-governing irrigation systems are integral to global food security and face serious problems under climate change. This is particularly true in areas expected to become more arid such as the Southwestern United States, where restrictive water rights are strictly enforced. Adaptations to these dual climatic and legal challenges include user-selected rules. In particular, during water shortage self-governing irrigation systems often change water allocations between members and rotate water delivery. However, it is unclear how these rules interact with each other as configurations and with contextual factors, such as the degree of water scarcity. It is also unclear how these rules influence outcomes between irrigators closer to the water source and those farther from it. How might different configurations of rules interact with water availability to produce outcomes along an irrigation system's canal network? This study addresses this question by exploiting a natural experiment in water distribution and allocation rules during shortage among a stratified sample of 60 snowmelt dependent irrigation systems in the San Luis Valley of Colorado during a four-year drought period from 2011-2014. A key finding is that the combination of rotational delivery and flexible water allocations produces the most equal crop growth between irrigators at the head and tail of the irrigation system at all levels of water availability. The marginal productivity of water at the head and tail end of irrigation systems at all levels of water availability is also equalized under this configuration. These results suggest a greater likelihood of ongoing collective action, important for climate change adaptation. However, rotation with flexible allocations is outperformed by other configurations depending on context. These findings highlight the configurational relationships between rules, further illustrate interactions between rules and physical context, and caution against panaceas in water resource management and climate change adaptation.
\end{abstract}

Key Words: adaptation; climate change; Colorado; common pool resources; institutions; irrigation; rotation; San Luis Valley; shortage sharing

\section{INTRODUCTION}

\section{Climate change and self-governing irrigation systems}

Improving global food security will be made more challenging by a changing climate (Turral et al. 2011, Wheeler and von Braun 2013, Bell et al. 2016). Because climate change will alter water supplies, irrigated agriculture in particular will suffer (Gleick 2003, FAO 2012). This is especially true for irrigators who rely on snowmelt (Vicuña et al. 2012, Villamayor-Tomas 2012). This is problematic because irrigation is expected to be responsible for meeting growing demands for food and already accounts for $40 \%$ of the world's food supply (UNESCO 2012). Worldwide, about three quarters of irrigated cropland and one quarter of all cropland relies on self-governed irrigation systems (Mabry 1996), and $90 \%$ of all irrigation systems are small-scale and self-governed (Cifdaloz et al. 2010). An irrigation system, i.e., the diversion dam, diversion structure, canals, weirs, sluices, and other infrastructure, is self-governed when farmers with rights to access the water conveyed by the system own, operate, maintain, and manage the system. Thus, irrigators themselves will be tasked with the vast majority of adaptation, yet scholars, policymakers, and irrigators themselves may not know enough to be adequately prepared for climate change (Kramer et al. 2017).

Farmers in the state of Colorado are a good test case for questions related to climate change adaptation in irrigated agriculture. Just over half of the farmland in Colorado is irrigated by selfgoverning irrigation systems (Sax et al. 2006, USDA 2014), and about four fifths of stream flow start as snow (CCC, n.d.). Although potentially offset by $\mathrm{CO}_{2}$ fertilization and an extended growing season (Wiltshire et al. 2013, Deryng et al. 2016), farmers nevertheless face mounting climate change challenges: more severe forest fires and forest composition changes (Lukas et al. 2014), declines in snowpack volume and earlier spring melt (Llewellyn and Vaddey 2013, Koirala et al. 2014), and increased crop water demand due to rising temperatures (Lukas et al. 2014). The part of the Rio Grande Basin commonly called the San Luis Valley (SLV), in which a community of 50,000 irrigates between 140,000 and 200,000 hectares, may be the most negatively impacted in Colorado and has already seen climatic changes (Mix et al. 2011, 2012, Lukas et al. 2014). Early signals of climate change have already prompted responses from irrigators, especially those dependent on groundwater (Cody et al. 2015, Smith et al. 2016).

Many scholars, policymakers, and irrigators see improvements to irrigation systems as important to adaptation (FAO 2012, Lee et al. 2014). Some of the improvements envisioned are institutional changes; that is, changes to laws, policies, rules, and norms (Kenney 2005, Ostrom 2005, Huntjens et al. 2012, Meinzen-Dick 2014). Particular attention has been paid to property rights to water (Cody 2018). However, property rights can be very difficult to change, and government-imposed rule changes are often resisted (Poteete et al. 2010). To compensate, irrigators on selfgoverning systems have developed local adaptations to shortage that manipulate two of the major influences on water use they control: rules governing water allocation and water distribution among members (Dinar et al. 1997, Joshi et al. 1998). My study investigates the effectiveness of two common drought responses of irrigation systems, (1) water delivery via rotation and (2) 
Fig. 1. Map of the San Luis Valley (SLV) depicting major rivers and watercourses; diversion structures, canals, and service areas of sampled systems; and the service areas of systems not sampled (data from the Colorado Division of Water Resources).

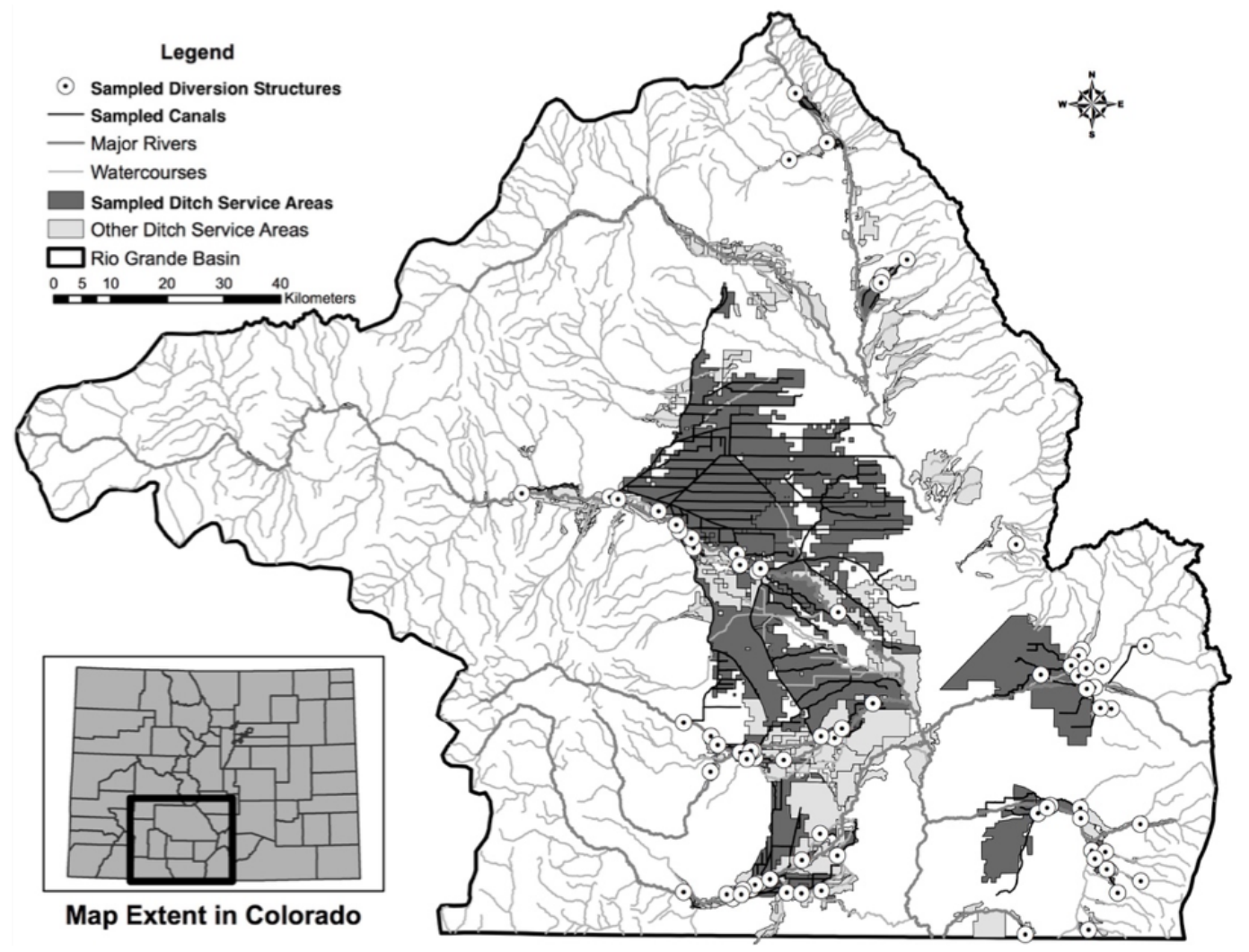

shortage sharing, in four configurations: rotation with shortage sharing, rotation without shortage sharing, simultaneous delivery with shortage sharing, and simultaneous delivery without shortage sharing. Effectiveness is evaluated at different levels of water shortage and for water users at different points along the irrigation system's water conveyance network. Rotation is defined as water delivery that occurs in turns, regardless of the duration of the turns or the sequence of delivery. Shortage sharing is defined as the alteration water allocations between users of the same irrigation system in times of drought, regardless of the original criteria used to allocate water (land owned, private rights held, historical use, etc.).

The Common Pool Resource (CPR) literature has begun to emphasize the configurational nature of rules (Baggio et al. 2016), but there is still much to learn about how different configurations influence the outcomes of CPR governance, such as equity (Ingram et al. 2008). Fairness and equality are of utmost importance: many studies have shown that perceptions of fairness in a self-governing CPR context are important for maintaining the collective action necessary to maintain the flow of resources to users (Arnold 2008, Poteete et al. 2010, Cody et al. 2015, Pérez et al. 2016, McCord et al. 2017). In irrigation, a ubiquitous issue is the potentially highly unequal relationship between irrigators upstream (head-enders), which have the ability to withdraw water first and in the largest amounts, and downstream (tail-enders), who must wait for water to flow past head-enders and can only take what is left (Janssen et al. 2011, 2012). Additionally, different levels of water shortage should generate different irrigation outcomes even with the same rules in place, as Cody (2018) found with respect to water rights. Therefore, I evaluate the effectiveness of the aforementioned configurations at different levels of water shortage and for fields at different distances from the irrigation system's main diversion.

To do this, a natural experiment in the use of rotation and shortage sharing during a period of drought (2011-2014) in the SLV was exploited. Drought creates the water shortage that triggers the implementation of the rotation and shortage sharing rules under study, and these rules serve as the different treatments. Hydrologic, technological, agronomic, and remotely sensed crop data (Normalized Difference Vegetation Index, NDVI) were paired with data on over 6700 individual fields nested within 60 self-governing irrigation systems for the years 2011-2014. The data are complemented by a stratified irrigation manager survey conducted in 2013 that assessed the rules in use of those systems, among other features. The study area and sampled irrigation systems are depicted in Figure 1. Because variables of interest are time invariant, the data were analyzed one year at a time using Ordinary Least Squares (OLS) linear regression and logistic regression with standard errors clustered by irrigation system. Tobit regression and spatial error and spatial lag models were performed as robustness checks. 
The results show that not only are these configurations significant predictors of irrigation performance, but there is also a significant interaction between the configurations and context. The rule configurations have significantly different impacts on the degree to which head-end fields and tail-end fields have divergent levels of crop production, and these effects are further moderated by the amount of water available. In particular, rotational delivery with shortage sharing, the most frequent combination of rules in the sample, has the capacity to equalize NDVI between headenders and tail-enders across all levels of water shortage. It also produces nearly equal marginal productivity of water, i.e., increases in crop growth per additional unit of water, between head-enders and tail-enders across all levels of water shortage. Rotation with shortage sharing consistently performs well compared to other configurations with less equal outcomes, even if in some water shortage conditions other configurations outperform it. Because of its more equal outcomes, and because it competes well with other configurations in drought, it is likely that rotational delivery with shortage sharing best promotes the collective action necessary to adapt self-governing irrigation systems to a more arid and unpredictable future in the SLV and elsewhere. That said, the precise forms of rotation and shortage sharing cannot be prescribed from this analysis. Indeed, in some cases, only rotation, only shortage sharing, or neither rule may be warranted. Further investigation of individual irrigation systems would be necessary to determine the exact rules that would optimize performance under a diverse set of conditions (Cifdaloz et al. 2010, Pérez et al. 2016). Nevertheless, this study gives irrigators and managers more certainty about the outcomes of the options they have.

\section{Rotation and shortage sharing: influences and interactions}

Two universal institutional features of self-governing irrigation systems are water allocation rules and water distribution rules (Ostrom 1992, Dinar et al. 1997, Joshi et al. 1998). They are especially worthy of study because of their direct and fundamental influence on water use, and therefore water demand and ecological impacts. In the context of irrigation, water allocation rules pertain to how much water each farmer within an irrigation system can use (e.g., 9200 cubic meters per hectare of land owned), and distribution rules determine how that water reaches the farmer (e.g., for sequential 12-hour turns; Ostrom 1992, Dinar et al. 1997, Joshi et al. 1998). One of each of these types of rules is the focus of this study, because they are known adaptations to shortage (Abdullaev et al. 2006, He et al. 2012) and are therefore likely to be important for adaptation to climate change. They determine (1) whether or not water allocations can be changed between individual irrigators on the same irrigation system (i.e., shortage sharing, de facto temporary transfers of the usufruct water right), and (2) whether the flow of the ditch is delivered to individual irrigators in a rotation or divided among them simultaneously. Irrigation systems in the SLV under normal water availability may or may not rotate, with some switching to rotation and some changing the rotation itself during shortage. However, although there are myriad manifestations of these rules in practice (e.g., multiple forms of rotation, multiple criteria for determining water allocations), some level of abstraction is required to make general inferences about their influence, and so they are considered binary in this study.

Delivery and allocation rules interact with key human and hydrologic behaviors, specifically the incentive to overuse or steal water and the fact that water is lost to seepage and some evapotranspiration down the length of an earthen canal. Irrigation managers in the SLV reported anywhere from 5-15\% losses depending on the distance a farmer's headgate is from the diversion structure, the slope of the ditch, soils, ditch lining (e.g., concrete, bentonite, nothing), vegetation along the ditch, height of the water table, etc. This implies that seepage loss can become a major factor for irrigators to consider during shortage. Most irrigation managers also reported some level of water theft, usually more damaging during shortage and on larger systems in which monitoring is difficult.

Important for this study, water rights in the SLV are administered by the state of Colorado at the point in which water is diverted from the natural water source through a human-made diversion structure and into the human-made irrigation network. Beyond the diversion structure, the state does not directly interfere with how water is allocated on the irrigation system. The allocation and distribution rules being investigated were adopted by irrigators themselves based on the coevolution of contextual factors, such as law and geography, and irrigator preferences (Ostrom 2014). The decision to implement institutional adaptations to shortage such as rotation or shortage sharing is generally based on snowpack or streamflow and determined by an informal dialogue between irrigators, though it may be taken to a vote. Irrigators on the same irrigation system usually interact almost daily during irrigation season, and nearly all systems have an annual meeting prior to the season to discuss the ongoing needs of the system, potential changes, and whether to implement adaptations to shortage. The process of rule adoption is deeply historical; irrigators in this region have been continuously operating their systems as far back as the 1850s and pass land down largely from fathers to sons. Therefore, in a highly pathdependent process (North 1990), these distribution and allocation rules have evolved slowly over time to accommodate new users, new technologies, changes in water law, changes in the hydrologic context, and other influences. Depending on the collective choice rules of the irrigation systems, operational rules of allocation and delivery are selected through majority vote, consensus, inherited tradition, hegemonic behavior of a few powerful irrigators, or some other decision process. Whatever the case, each configuration is ultimately the product of coevolving contextual factors and irrigator preferences (Ostrom 2014). Irrigators report that changes to their rules have produced meaningful changes in crop production in the past, and among irrigators the importance of allocation and distribution rules is widely acknowledged.

Looking first at delivery rules, under rotation users can easily monitor each other at the main canal as they take turns diverting water. Monitoring in the SLV is conducted almost exclusively by eye. There are very few irrigation systems in which electronic ditch gates and gages are in use. Under rotation, the next farmer in turn will be at the ditch, engaged in de facto monitoring, sometimes in the middle of the night. Although requiring increased negotiation, management, and operational costs, rotation thus helps prevent "stationary bandit" behavior (Janssen et al. 2011, 2012), wherein head-enders take advantage of being first in line to extract water and deprive tail-enders of their full allocation (Ostrom 1992, Lam 1998). If left unchecked, stationary bandits eventually cause tail-enders to become helpless to match the elevated extraction of head-enders, and in extreme cases, tailenders get no water at all. In contrast, rotation creates an 
affirmative requirement to deliver water to all users, potentially improving collective action through time (Dayton-Johnson 2000, Pérez, et al. 2016).

Because rotation generally allows the full flow of the ditch to reach each irrigator, it has four importantly different hydrologic impacts compared to simultaneous delivery: (1) rotation generates enough hydraulic head to push sufficient water the full length of the ditch (Lam 1998); (2) rotational pulses more quickly saturate the root zone over a given area of land when compared to continuous application of the same volume; (3) during very high flows, rotation can overwhelm and damage infrastructure, waste water, overwhelm crops, and erode soils; and (4) depending on how turns are taken, rotation may cause water to flow over a dry ditch bed at the start of turns, increasing seepage losses compared to simultaneous delivery, which keeps the ditch bed wet constantly.

On systems that distribute simultaneously, the flow is divided among users according to de facto rights between them at the same time. Three key features of simultaneous delivery include: (1) greater transaction costs to establish monitoring and more difficulty in monitoring because of the need to monitor many water users at once, and thus less monitoring overall; (2) no affirmative delivery requirement to tail-enders (or anyone, for that matter); and (3) decreases water supply reliability to tail-enders because of divided hydraulic head and thus worse seepage losses relative to rotation. Together, these features encourage theft and hegemony by head-enders as well as potentially more severe seepage losses. However, they may also ensure predictability of flow for most users most of the time. Simultaneous delivery is also inexpensive to organize and administer in terms of time and labor. Finally, the lack of turn-taking simplifies transfers, infrastructure needs, and maintains a consistently saturated ditch bed over the distance that water flows, eliminating the need to repeatedly saturate the bed when rotating turns.

The other rule in use under consideration, shortage sharing, implies flexibility in the ownership of de facto water rights. This flexibility should allow for more efficient allocations of water, enabling irrigators to improve the vigor of already planted crops, reliably plant more area, and earn revenue on unused water ( $\mathrm{He}$ et al. 2012). Shortage sharing should improve marginal productivity in most cases by allocating water to lands with greater needs. Without the flexibility of shortage sharing, there is likely to be lower aggregate production than could otherwise be achieved. However, this flexibility can also increase the costs of monitoring water use by creating ambiguous water rights. Higher monitoring costs introduced by shortage sharing could lead to lower levels of monitoring, thus encouraging water theft and reduced irrigation performance, especially for tail-enders. However, if rotation is in place, this effect may be mitigated. Furthermore, shortage sharing will alter the hydraulic head, seepage loses, and return flows from irrigation applications not fully consumed. This would harm tail-enders relative to headenders and would be more damaging under simultaneous delivery because of the lack of an affirmative delivery requirement.

\section{Hypotheses and predictions}

The consequences of one rule depend on the adoption of the other rule, leading to hypothesis $1(\mathrm{H} 1)$ : the effect of shortage sharing on irrigation performance depends on how water is being delivered, and the effect of the delivery method on irrigation performance depends on whether shortage sharing is practiced. Using rotation, with higher monitoring and higher hydraulic head, shortage sharing will be helpful because of increased flexibility, thus allowing water to flow to fields most in need. Under simultaneous delivery, with lower monitoring and lower hydraulic head, shortage sharing will be harmful due to stationary bandit behavior and seepage losses. Without shortage sharing's increased flexibility, rotation may be harmful because of the rate of flow being variable and thus water may be insufficient for or overwhelm infrastructure, soils, or crop demand. Finally, without shortage sharing, simultaneous delivery will tend to produce stationary bandit behavior and, in severe shortage, difficulty generating enough hydraulic head to move water the full length of the irrigation system.

The effects of the rules in use will depend on water availability and how far water has had to flow from the diversion structure to the field, leading to hypothesis $2(\mathrm{H} 2)$ : the effects of shortage sharing and delivery rules on irrigation performance are moderated by the amount of water diverted by the irrigation system and a field's distance from the diversion. Rotational delivery should equalize irrigation performance between headenders and tail-enders regardless of water availability and shortage sharing rules, but without shortage sharing could prove inflexible to changes in water availability, leading to worse performance as higher levels of water availability overwhelm the system. Shortage sharing should harm tail-enders under simultaneous delivery, especially in extreme drought. But with rotation, shortage sharing should stabilize irrigation performance at higher levels of water availability through more efficient transfers. Rotation with shortage sharing, however, should harm performance at low levels of water availability due to the hydrologic inefficiencies of turn taking and the agronomic problems associated with very few pulses of irrigation water Under simultaneous delivery without shortage sharing, there should be high inequality between the head and tail-ends and marginal productivity of crop per unit of water should be higher for head-enders who will capture the water ahead of tail-enders.

\section{METHODS}

Careful case selection for natural experiments is increasingly encouraged when research questions cannot be answered using a laboratory, field experiments, or modeling; when study systems involve many different biophysical and social data; and when data are difficult or impossible to acquire or aggregate (Poteete et al. 2010, Cox 2015). Natural experiments, such as this study, require data about numerous potentially confounding variables, and these data are seldom available at the same unit of analysis or resolution. However, the SLV overcomes many of these challenges because of the richness of its public data, the stability of the units of analysis, and six years of site visits by the author to ground truth the data and analysis. A period of drought in the SLV from 2011-2014 enables an evaluation of the rules in use during shortage, which serve as the different treatments in the study design.

\section{Data collection and variable selection}

Variables were drawn from CPR theory and organized using the Institutional Analysis and Development Framework (Ostrom 2005). Variables were also selected in part because of their use to previous studies of irrigation in this region (Cox 2010, Smith 2016). The overall approach to the study is depicted in Figure 2. 
Fig. 2. A flow diagram containing the variables used in the analysis. The variables in italics are the independent variables of interest, whereas the rest are controls. The dependent variables are listed under Irrigation Performance. The variables selected are known to be important from the Common Pool Resource (CPR) literature and their relationships are structured using the Institutional Analysis and Development framework (Ostrom 2005, Poteete et al. 2010). Contextual variables, such as water availability and water diversion, influence the decisions actors make in the action arena, considered here to be the user-governed ditch system. User decisions are shaped by features that apply to the irrigation system as a whole, as well as features of individual irrigated fields. Outcomes of these processes include the decision to irrigate a field, how extensively, and the resulting crop growth. Note: NDVI $=$ Normalized Difference Vegetation Index.

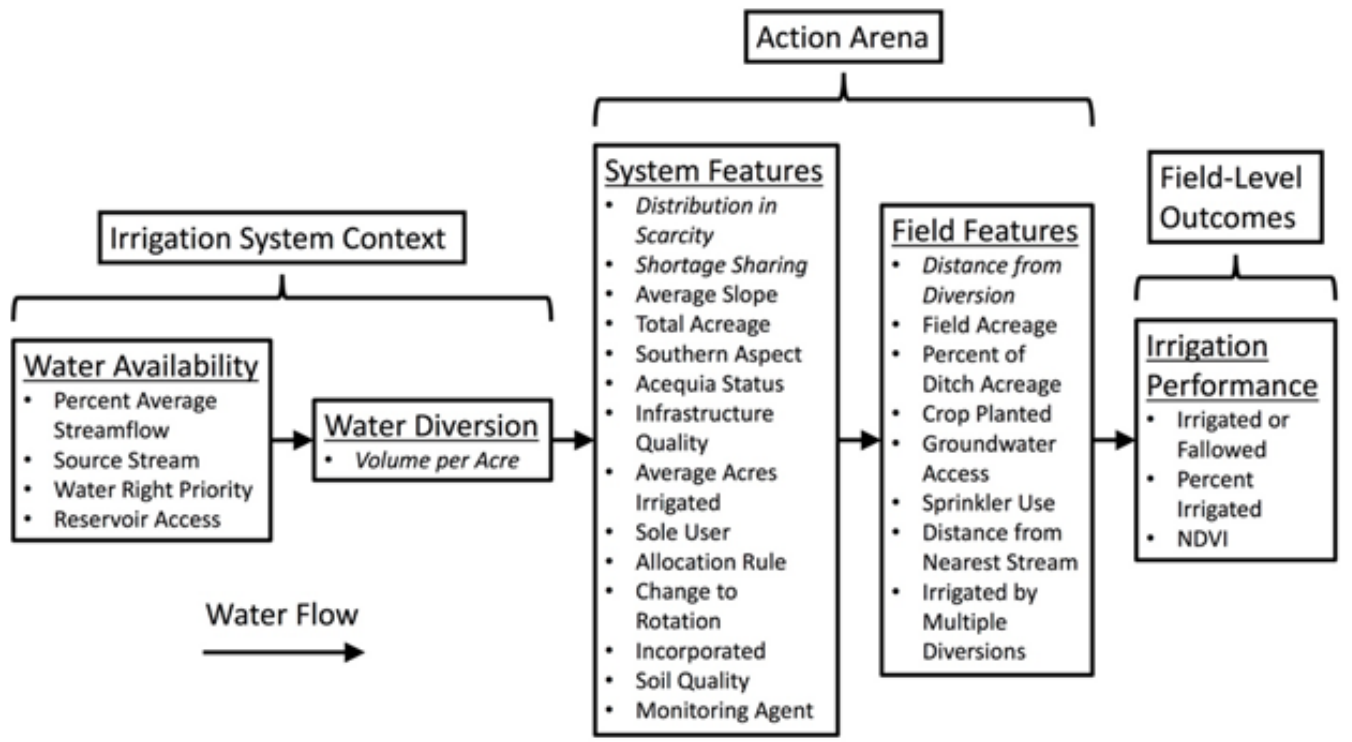

Water flows from left to right, being influenced by the variables in the diagram along the way. All the variables shown in Figure 2 are used in the regression analyses. Table 1 also provides this information with more detail about the variables.

Data were collected from various public sources, primarily the Colorado Department of Natural Resources' Rio Grande Decision Support Systems (RGDSS), the United States Geologic Survey, and GoogleEarth Engine (e.g., NDVI and elevation rasters). For the purposes of the regressions, irrigation systemlevel data were applied to the field observations to assess irrigation outcomes for individual fields. Figure 3 illustrates how NDVI raster data from GoogleEarth Engine, July 2013, were overlaid by individual fields and irrigation system boundaries from RGDSS, shown as vectors. When calculating the average NDVI value for each field, the vector data were converted into raster data to compute zonal statistics in ArcGIS 10.5.

Data were also collected using surveys of a stratified sample of 60 irrigation system leaders in 2013 to assess rules in use and other irrigation system features. Stratification was done by groundwater access (access/none), water right priority (senior/junior), geographic location (upstream/downstream), geographic location (four major watersheds), and cultural heritage (founded by the Spanish or by the Americans). The sample may therefore not be representative of the SLV overall, but it will be better able to determine whether underlying effects exist that would otherwise go undetected if the sample were not balanced on these key variables. Surveys were administered in English and conducted in person at a location of the interviewee's choosing by two to three researchers at a time. One researcher led the questioning and recording of responses, and the others took notes and confirmed accuracy. To ensure that questions were asked and answers recorded consistently, the groups of researchers were mixed each day.

There are some limitations to the data. For example, the study lacks farm-level data and therefore cannot account for farm-level effects. However, fields nearer to each other are more likely to be owned by the same farm, and so the spatial regressions take some farm-level effects into account passively. The study also lacks any direct data on the wealth available to irrigation systems or individual farmers. That said, the area of an irrigation system is a proxy for the wealth and labor available to that irrigation system for operations and maintenance. Distinct patterns of natural resource use can be the product of distinct economic relationships (Kininmonth et al. 2016). Therefore, a dichotomous variable indicating whether an irrigation system was founded by the Spanish (acequia) is included. This provides socioeconomic and demographic information because those systems tend to be more collectivist, less capital intensive, physically smaller, less market oriented, utilize animal fertilizers, grow heirloom crops, and have historically been persecuted, oppressed, and excluded from governance processes (Rivera 1998, Rodriguez 2006, Cox and Ross 2011, Cox 2014). The installation of sprinkler irrigation and irrigator-reported infrastructure quality are also proxies for the cost structure and capital available to individual farmers and the irrigation system (Bell et al. 2016). Irrigation system area also correlates with the number of irrigators, a key variable important for the extent of and difficulty of solving collective action 
Table 1. Variable descriptions, names, types, units, and summary statistics. A " $f$ " next to the shorthand name of the variable indicates a field-level variable. The rest of the variables are collected at the level of the irrigation system. A " $\dagger$ " next to the shorthand name of the variable indicates a time-variant variable. The rest of the variables do not change over time.

\begin{tabular}{|c|c|c|c|}
\hline Variable Explanations & Shorthand Name & Variable Type; Units & Summary Statistics \\
\hline $\begin{array}{l}\text { Irrigation system rotates water delivery in } \\
\text { scarcity }\end{array}$ & ROT_SRC & Binary & $\begin{array}{c}\text { N: } 60 \\
\text { Percent: } 60.00\end{array}$ \\
\hline Irrigation system engages in shortage sharing & SHR_SRC & Binary & $\begin{array}{c}\text { N: } 60 \\
\text { Percent: } 65.00\end{array}$ \\
\hline $\begin{array}{l}\text { Percent of maximum field distance from } \\
\text { diversion }\end{array}$ & DIV_DIST $f$ & Percentage & $\begin{array}{c}\text { N: } 6711 \\
\text { Min: } 0.00 \\
\text { Med: } 55.50 \\
\text { Mean: } 54.92 \\
\text { Max: } 100.00 \\
\text { SD: } 22.06\end{array}$ \\
\hline $\begin{array}{l}\text { Volume of water diverted per unit area of } \\
\text { irrigation system }\end{array}$ & AFDIV_PERDACRE $\dagger$ & $\begin{array}{c}\text { Continuous; } 3083.7 \text { cubic meters per } \\
\text { hectare } \\
\text { (acre-feet/acre) }\end{array}$ & $\begin{array}{l}\text { N: } 239 \\
\text { Min: } 0.00 \\
\text { Med: } 1.27 \\
\text { Mean: } 2.06 \\
\text { Max: } 13.41 \\
\text { SD: } 2.34\end{array}$ \\
\hline Field irrigated or fallowed & IRRFAL $f \dagger$ & Binary & $\begin{array}{c}\text { N: } 26844 \\
\text { Percent: } 57.71\end{array}$ \\
\hline Percent field area irrigated & PMIA $f \dagger$ & Percentage & $\begin{array}{c}\text { N: } 26844 \\
\text { Min: } 0.00 \\
\text { Med: } 70.99 \\
\text { Mean: } 50.92 \\
\text { Max: } 100.00 \\
\text { SD: } 45.66\end{array}$ \\
\hline $\begin{array}{l}\text { Normalized Difference Vegetation Index } \\
\text { (NDVI) of field }\end{array}$ & NDVI $f \dagger$ & Continuous & $\begin{array}{c}\text { N: } 26844 \\
\text { Min: } 0.000 \\
\text { Med: } 0.489 \\
\text { Mean: } 0.455 \\
\text { Max: } 0.883 \\
\text { SD: } 0.260\end{array}$ \\
\hline Name of surface water source & WATER_SRC & Categorical & $\begin{array}{c}\text { N: } 60 \\
\text { Rio Grande: } 13 \\
\text { Conejos River: } 10 \\
\text { Alamosa River: } 7 \\
\text { La Jara Creek: } 6 \\
\text { Culebra Creek: } 5 \\
\text { San Antonio River: } 4 \\
\text { San Francisco Creek: } 3 \\
\text { Rito Alto: } 2 \\
\text { Kerber Creek: } 2 \\
\text { Rito Seco: } 1 \\
\text { Costilla Creek: } 1 \\
\text { South Cuates: } 1 \\
\text { San Luis Creek: } 1 \\
\text { Sangre de Cristo Creek: } 1 \\
\text { Vallejos: } 1 \\
\text { Ventero Creek: } 1 \\
\text { Torcido: } 1\end{array}$ \\
\hline $\begin{array}{l}\text { Irrigation system incorporated as nonprofit } \\
\text { mutual ditch company }\end{array}$ & INC & Binary & $\begin{array}{c}\text { N: } 60 \\
\text { Percent: } 40.00\end{array}$ \\
\hline $\begin{array}{l}\text { Irrigation system founded by Hispanics } \\
\text { between } 1850-1880\end{array}$ & ACEQUIA & Binary & $\begin{array}{c}\text { N: } 60 \\
\text { Percent: } 53.33\end{array}$ \\
\hline $\begin{array}{l}\text { Quality of irrigation system infrastructure } \\
\text { deemed problematic }\end{array}$ & INFRA & Binary & $\begin{array}{c}\text { N: } 60 \\
\text { Percent: } 40.00\end{array}$ \\
\hline Access to a surface reservoir & RES & Binary & $\begin{array}{c}\text { N: } 60 \\
\text { Percent: } 41.67\end{array}$ \\
\hline $\begin{array}{l}\text { Percent maximum area of irrigation system } \\
\text { irrigated on average from 1984-2015 }\end{array}$ & PERMAXACIRRAVE & Percentage & $\begin{array}{c}\text { N: } 60 \\
\text { Min: } 2.63 \\
\text { Med: } 66.10 \\
\text { Mean: } 67.73 \\
\text { Max: } 116.81 \\
\text { SD: } 18.72\end{array}$ \\
\hline
\end{tabular}




\begin{abstract}
Average slope of irrigation system
Water right priority rank of irrigation system

Irrigation system owned by a single farmer

Irrigation system appoints a monitoring agent

Irrigation system allocates water based on land owned or needs of the farmer

Quality of irrigation system soil deemed problematic

Irrigation system switches to rotational delivery in scarcity

Field distance to nearest stream
\end{abstract}

Area of the field

Field's percentage of total irrigation system area

Total area of the irrigation system

Field irrigated by multiple diversions

Irrigation system has south-facing aspect

Percent average annual runoff at upstream gage nearest the diversion structure

Field uses sprinkler irrigation

Current or most recent crop grown on a field

Field has groundwater access
SLOPE

Continuous; Degrees

WDPRIOR

SOLEUSER

Binary

MONITOR Binary

LANDNEED

Binary

SOIL

CNG2ROT

STRM_DIST $f$

Binary

Binary

Continuous; Kilometeres

BASEACRES $f$

ACREPER $f$

Percentage

DACRES

Continuous; 0.4 hectares (acres)

MULTD $f$

Binary

SOUTH

Binary

PERAVAFGAGE †

Percentage

SPRINK $f \dagger \quad$ Binary

CROP $f \dagger$

Categorical
N: 60

Min: 0.08

Med: 0.46

Mean: 0.67

Max: 5.37

SD: 0.79

N: 60

Min: 1

Med: 24.50

Mean: 52.03

Max: 311

SD: 65.83

N: 60

Percent: 11.67

N: 60

Percent: 55.00

$\mathrm{N}: 60$

Percent: 21.67

N: 60

Percent: 23.33

N: 60

Percent: 16.0

N: 6711

Min: 0.00

Med: 2018.60

Mean: 2734.20

Max: 11488.00

SD: 2488.75

N: 6711

Min: 0.06

Med: 24.81

Mean: 54.65

Max: 759.86

SD: 59.79

N: 6711

Min: 0.000407

Med: 0.150320

Mean: 0.894050

Max: 100.00

SD: 3.79

N: 60

Min: 29.24

Med: 1122.40

Mean: 8868.20

Max: 117320.00

SD: 20840.00

$\mathrm{N}: 6711$

Percent: 19.74 $\mathrm{N}: 60$

Percent: 20.00

$\mathrm{N}: 240$

Min: 6.07

Med: 62.79

Mean: 61.25

Max: 100.00

SD: 25.31

N: 26844

Percent: 31.23

N: 26200

Alfalfa: 9752

Grass pasture: 10928

Potatoes: 2262

Small grains: 2960

Other: 298

N: 26844

Percent: 42.39 problems faced by irrigators. Finally, for systems using rotational delivery, the data lack information on the rotation itself, e.g., the location on the canal of each irrigator, the order in which they may take water, the duration of each farmer's turn, etc.
Finally, over time, irrigation systems adopt rules based on the feedback irrigators receive from past performance (Ostrom 2014). It could therefore be argued that the effects for different rules in use actually reflect past irrigation performance and/or the factors 
Fig. 3. A map illustrating a Normalized Difference Vegetation Index (NDVI) raster overlaid by field and irrigation system vector data (data from the Colorado Division of Water Resources).

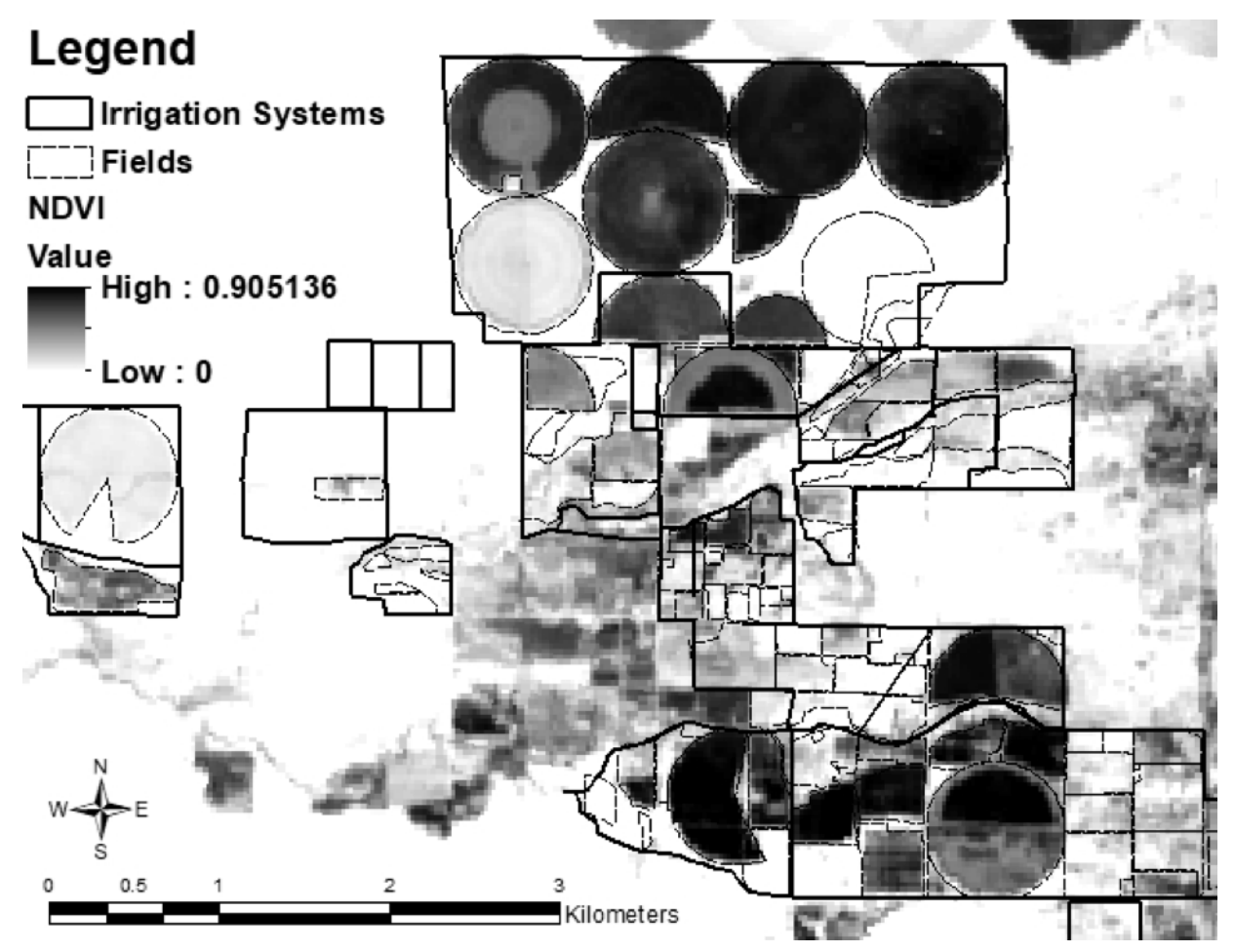

shaping past irrigation performance and not the current rules. However, the parsimonious explanation that arises from the data is that the causal explanations are straightforward: the rules cause the outcomes (see Appendix 1, Section 9). Most importantly, the selection story and endogeneity argument presume that rules have real-time effects on performance, i.e., if performance responds to certain rules, irrigators will presumably alter rules to take advantage of these effects. Without that causal link, there is no selection pressure on the rules and there is no endogeneity. This study embraces that causal link, but argues that the feedbacks take too long and are too weak in the near-term to overwhelm the carefully designed analyses reported here. Irrigators report a highly cautious and slow-moving approach to institutional change at the level of the irrigation system, as well as the active influence of rules on outcomes of the system (especially in drought and on the equality of head and tail-enders). Furthermore, because rules assessed in 2013 can't have been shaped by performance in 2014 , because the regressions account for other drivers of performance and rule choice, because the sample was stratified for important factors that drive performance and rule choice, and because of the content of the 60 interviews and other conversations with key stakeholders and informants, it is reasonable to interpret the results in a straightforward way.

\section{Analytical methods}

Following Gujarati and Porter (2009), OLS and logit regressions were run in R 3.2.2 (R Core Team 2015) for all years in the study period for three dependent variables: irrigated vs. fallowed/not irrigated (logit), percentage irrigated (OLS), and NDVI (OLS).
Using Primo et al. (2007) as a guide, the analysis is not a hierarchical model but instead uses OLS and logit regression with clustered standard errors at the level of the irrigation system. This is because the data exist only at two levels (field and irrigation system), the measure of interest is the average effect of the rules in use across systems, and fixed effects would obscure the rules in use. The models are run for each year as robustness. To specify the model, an iterative process was conducted between consulting theory and running correlations, pair-wise regressions, and analysis of variance to assess which of the available variables to include in the regressions. Variables that were not deemed sufficiently explanatory or were not especially warranted by theory were excluded from the final regression. The model without interactions takes the form:

$$
\begin{aligned}
& y_{i}=\beta_{0}+\beta_{1} \text { SPRINK }_{i}+\beta_{2} \text { CROP }_{i}+\beta_{3} \text { GROUND }+\beta_{4} \text { WATER_SRC } \\
& +\beta_{5} I_{N C}+\beta_{6} \text { SOUTH }_{i}+\beta_{7} \text { ACEQUIA }_{i}+\beta_{8} \text { INFRA }_{i} \\
& +\beta_{9} R E S_{i}+\beta_{10} \text { PERMAXACIRRAVE } E_{i}+\beta_{11} S L O P E_{i} \\
& +\beta_{12} W_{\text {WPRIOR }}+\beta_{13} \text { STRM }_{-} D I S T_{i} \\
& +\beta_{14} \text { BASEACRES }_{i}+\beta_{15} \text { ACREPER }_{i}+\beta_{16} \text { DACRES }_{i} \\
& +\beta_{17} \text { MULTD }_{i}+\beta_{18} \text { PERAVAFGAGE } \\
& +\beta_{19} \text { MONITOR }_{i}+\beta_{20} \text { LANDNEED }_{i}+\beta_{21} \text { SOIL }_{i} \\
& +\beta_{22} \text { CNG } 2 R O T_{i}+\beta_{23} \text { DIV }_{-} D I S T_{i}+\beta_{24} \text { SHR }_{-} S R C_{i} \\
& +\beta_{25} \text { ROT_SRC }{ }_{i}+\beta_{26} \text { AFDIV_PERDACRE } i \\
& +\beta_{27} \text { SOLEUSER }_{i}+\varepsilon_{i}
\end{aligned}
$$

Interactions between shortage sharing (SHR_SRC) and rotational delivery (ROT_SRC) were conducted to assess the first hypothesis. To assess the second hypothesis, a categorical variable with five categories (the four potential institutional 
configurations plus seven systems owned entirely by one farmer) was interacted with volume diverted by the irrigation system per irrigable unit area on that system (AFDIV_PERDACRE) and percent of the maximum field distance from the diversion (DIV_DIST). South facing aspect (SOUTH), a ditch-level variable, which captures the intensity of direct sunlight, was only included in models using NDVI as the dependent variable. Data for irrigation method (SPRINK), crop grown (CROP), and groundwater access (GROUND) were for the most recent observation for that field given the year under analysis (i.e., fields not irrigated were given the most recent data available, usually the previous year). Data for volume diverted per irrigable unit area and percent average flow at the upstream gage (PERAVAFGAGE) were for the year under analysis. One ditch system lacked diversion volume data for 2014, and so it was excluded from the 2014 analysis.

Because percentage area irrigated and NDVI are censored variables, Tobit regressions were run to confirm the significance, size, and direction of the effects found using OLS. To explicitly account for spatial autocorrelation, spatial lag and spatial error models were also run (Bivand and Piras 2015). These robustness checks confirmed the OLS and logit results. Because the OLS and logit results are easier to interpret, they are reported below.

\section{RESULTS}

Hypothesis 1: interaction between rotation and shortage sharing

H1: The effect of shortage sharing on irrigation performance depends on how water is being delivered, and the effect of the delivery method on irrigation performance depends on whether shortage sharing is practiced.

Shortage sharing has a significantly different effect on outcomes under rotational delivery when compared to simultaneous delivery, and rotational delivery has a significantly different effect on outcomes under shortage sharing than under fixed allocations $(\mathrm{p}<0.05)$. When rotating, shortage sharing has no significant effect on outcomes in any year studied for any dependent variable measured. That said, the predicted values for rotation and sharing is higher than rotation alone for the vast majority of years and dependent variables. When not rotating, shortage sharing significantly harms outcomes in all years studied for all dependent variables measured, supporting predictions. Conversely, when sharing shortage, rotation improves outcomes in all years studied for all dependent variables measured, as predicted. However, when there is no shortage sharing, rotation significantly harms the probability of being irrigated in 2012 and 2014. In other years and for other dependent variables, there is no significant difference, though the model's predicted values are higher for simultaneous delivery and no shortage sharing in all years. This suggests agreement with the prediction that rotation without shortage sharing could have ambiguous effects.

Figure 4 depicts the probability of a field being irrigated in 2012 under the four different institutional configurations. The year 2012 is representative of the overall results. The probability of being irrigated is shown here because irrigating a field reflects a large commitment on the part of an irrigator that is often made prior to the beginning of the irrigation season. It is therefore a more conservative measure of the influence of rules on outcomes.
Fig. 4. A field's probability of being irrigated in 2012 under the four different institutional configurations evaluated: simultaneous delivery without shortage sharing, simultaneous delivery with shortage sharing, rotational delivery without shortage sharing, and rotational delivery with shortage sharing. I excluded seven irrigation systems with only one farmer to ease interpretation. When rotating, shortage sharing has no significant effect on the probability that a field is irrigated in any year studied. When not rotating, shortage sharing significantly reduces the probability that a field will be irrigated. Conversely, when sharing shortage, rotation significantly improves a field's probability of being irrigated, whereas without shortage sharing rotation has a significantly negative effect in 2012 and 2014. Confidence bands are at $95 \%$.

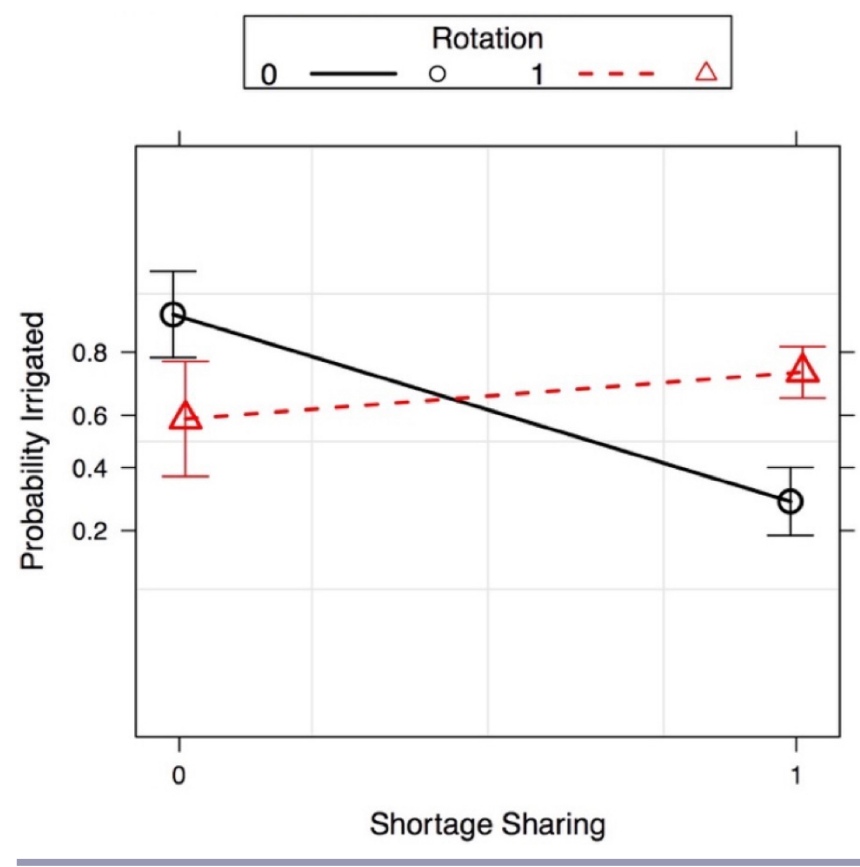

\section{Hypothesis 2: institutions interact with degree of scarcity and field distance}

H2: The effects of shortage sharing and delivery rules on irrigation performance are moderated by the amount of water diverted by the irrigation system and a field's distance from the diversion.

The second hypothesis is supported overall, though there are some circumstances in which interactions are not significant and in which results are unexpected. That said, the results illustrate similar trends across all outcome variables and across years, implying robust results. Rotational delivery mitigates inequality of irrigation performance between head-enders and tail-enders regardless of water availability and with or without shortage sharing. Rotational delivery without shortage sharing improves marginal productivity at the tail-end but is easily overwhelmed by increases in water availability without shortage sharing, leading to negative marginal productivity (i.e., more water decreases crop production). This exceeds predictions, which expected no or low positive marginal productivity and suggests physical damage. 
Table 2. The main findings from the analysis of the second hypothesis. Overall, the most equitable arrangement is rotational delivery with shortage sharing and the least equitable arrangement is simultaneous delivery with shortage sharing. Depending on position on the ditch and water availability, rotational delivery with shortage sharing and simultaneous delivery without shortage sharing compete for the most productive arrangements overall, while simultaneous delivery with shortage sharing is the least productive configuration overall. That said, each configuration is either the most or second most productive under some set of conditions consistently across years.

\begin{tabular}{ll}
\hline \hline $\begin{array}{l}\text { Configuration } \\
\text { Head vs. Tail Performance }\end{array}$ & Head vs. Tail Marginal Productivity \\
\hline $\begin{array}{l}\text { Sole Users } \\
\text { Tail-end fields perform better than head-end } \\
\text { fields at all levels of water availability. }\end{array}$ & $\begin{array}{l}\text { Tail-end fields are more responsive to } \\
\text { increases in water availability than head-end } \\
\text { fields. }\end{array}$ \\
& \\
$\begin{array}{l}\text { Simultaneous Delivery Without Shortage Sharing } \\
\text { At low levels of water availability, tail-enders } \\
\text { perform better than head-enders, but as water } \\
\text { availability increases head-enders outperform } \\
\text { tail-enders. }\end{array}$ & $\begin{array}{l}\text { Head-enders and mid-reachers are more } \\
\text { responsive to increases in water availability } \\
\text { than tail-enders, which eventually become } \\
\text { essentially unresponsive to increases in water } \\
\text { availability. }\end{array}$
\end{tabular}

Simultaneous Delivery with Shortage Sharing Across all levels of water availability, the tail- Head-enders and tail-enders are nearly end does worse than the head-end, especially equally weak if at all responsive to increases in extreme and moderate shortage. in water availability.

Compared to Other Configurations

Tail-end fields tend to perform as well as the other institutional configurations across all levels of water availability. However, sole users are consistently the worst performing for head-end fields and mid-reachers across all levels of water availability.

This institutional configuration is consistently the best or second-best performer for headenders in moderate, minor, and slight shortage. At lower levels of water availability, performance at the head-end becomes worst or second worst. However, this configuration is consistently the second-best performer at the tail-end for all levels of water availability.

Overall this configuration is the least responsive to increases in water availability. This institutional configuration is consistently the second-best performer at the head-end in extreme scarcity. But as water availability increases, performance at the head-end declines to worst or second worst. Tail-enders fare even worse than this; at all levels of water availability, they perform worst or second worst.

Rotational Delivery Without Shortage Sharing There is no significant difference between This configuration is the only instance of head and tail-enders under this configuration negative responsiveness; more water harms at any level of water availability. performance for both head and tail-enders.

Rotational Delivery with Shortage Sharing There is no significant difference between head and tail-enders under this configuration at any level of water availability.
Fields from the head to the tail of the ditch are nearly equally responsive to increases in water availability.
Overall, in extreme scarcity, this is the highest performing configuration up and down the ditch. In moderate scarcity, performance drops to best or second best. But when shortage is minor and slight, both head and tail-end performance drops to worst or second worst.

This institutional configuration has the least variation across years and across different combinations of field distance and water availability. At the head-end, as water availability increases, performance improves from worst to second best, while tail-end performance improves from third worst to best; the head and tail-end share shortage roughly equally.
Shortage sharing increases marginal productivity under rotation but diminishes marginal productivity to near zero under simultaneous delivery, especially at the tail-end. Shortage sharing also makes inequality worse under simultaneous delivery when compared to under rotation, especially in extreme shortage at the tail-end. The weakest differences between performance of the different configurations emerge at the head-end under extreme scarcity, with the tail-ends under minor and slight scarcity generating the largest differences in performance between institutional configurations. More detailed findings for each institutional configuration are given in Table 2.
Figures 5 and 6 illustrate the results by showing the interaction between rules in use, field distance from diversion, and volume diverted per unit area for 2012 using NDVI as the outcome. Figure 5 illustrates performance as one moves from the head-end to the tail-end of the system for different levels of water availability, whereas Figure 6 illustrates the marginal productivity of water at different points along the irrigation network. For these results, seven irrigation systems owned by only one farmer are included as counterfactuals to systems reliant on collective action. Results for NDVI are given here because NDVI represents a proxy for the other outcomes: lower NDVI values also correspond to lower 
Fig. 5. Head vs. tail-end performance at different levels of water availability. Each panel illustrates this relationship between a field's distance from the diversion structure and Normalized Difference Vegetation Index (NDVI) for a different value of volume diverted per unit area, corresponding to extreme, moderate, and minor shortage (the 10th, 50th, and 80th percentiles, respectively, of the 2011-2014 average volume diverted per unit area of the system). SDNS = Simultaneous Delivery with No Sharing; RNS = Rotation with No Sharing; SDS = Simultaneous Delivery and Sharing; $\mathrm{RS}=$ Rotation and Sharing; SOLE $=$ Sole User. Confidence bands are at $90 \%$.

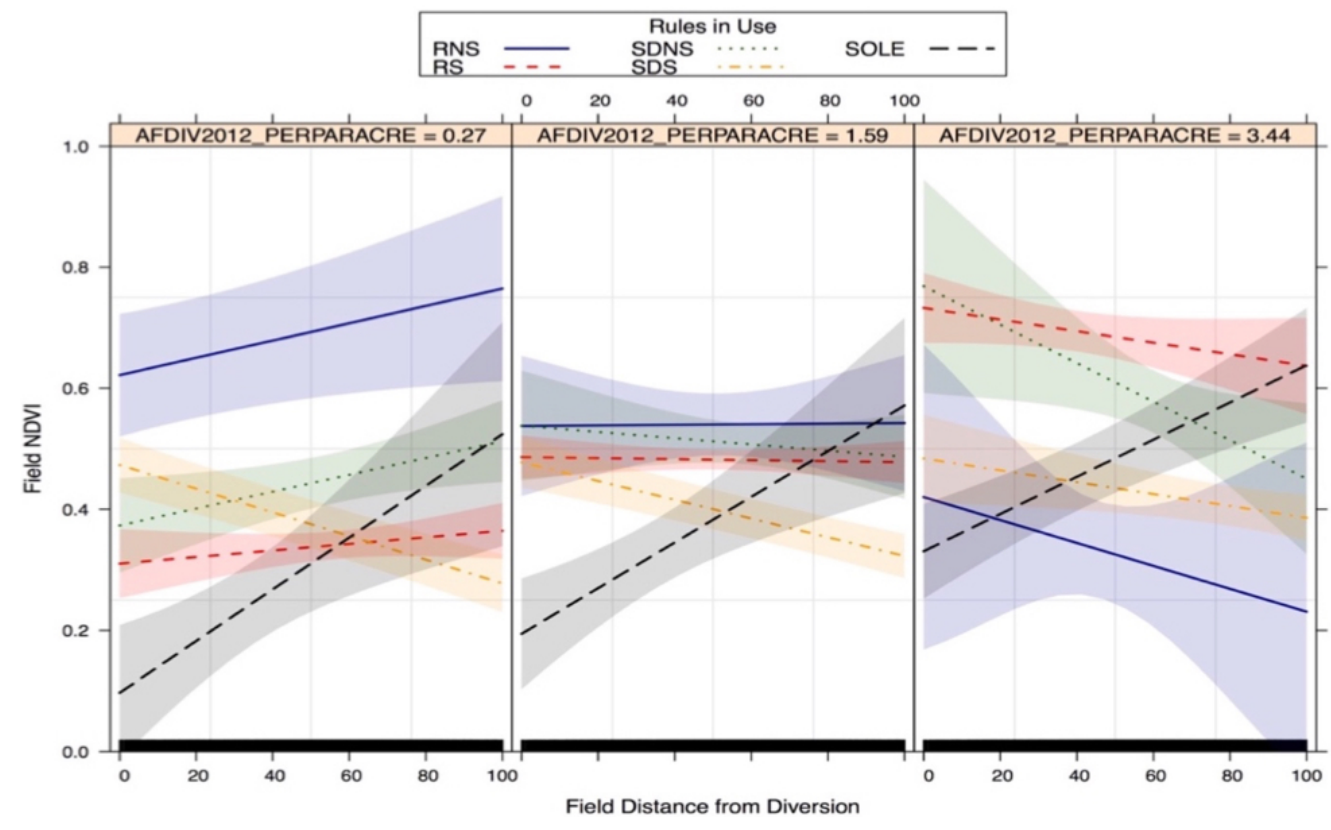

irrigated area, including no irrigation. The NDVI represents a better approximation of total crop growth, and therefore income and potential for subsistence, than irrigated area because NDVI also includes information about the intensity of crop growth and therefore the weight of sellable or consumable crop. In brief, NDVI gives a sense of both how extensive and intensive irrigation was.

\section{DISCUSSION}

This study advances the literature by considering the combined effects on irrigation performance of shortage sharing and delivery method. There are numerous studies that separately investigate shortage sharing (Torell and Ward 2010, D'Exelle et al. 2012, He et al. 2012, Ward et al. 2013) and rotation (Turral et al. 2002, Abdullaev et al. 2006, Janssen et al. 2012). However, complicating this literature, there is not agreement as to what constitutes shortage sharing. D'Exelle et al. (2013) investigated instances in which head-enders forego diversions with the intention of enabling tail-enders to irrigate (thus reducing the head-ender diversions disproportionately), finding that although this reduced efficiency, it improved equality. Ward et al. (2013) and Torell and Ward (2010) assessed various shortage sharing arrangements, finding that an equal percentage reduction in diversions by all irrigators was flexible, easily understood, and enhanced crop production when compared to shortage arrangements that applied unequal risk burdens. He et al. (2012) also studied several mechanisms of shortage sharing under Prior Appropriation in Alberta, Canada where changes to water allocations were made through various inflexible rules as well as markets. They found that all modes of shortage sharing were efficiency improvements over Prior Appropriation, with market exchanges being the most efficient (these findings were for intersystem sharing, not intrasystem sharing as in the present study). The overall message from the literature regarding shortage sharing is that it is beneficial, especially when it is congruent with contributions to system maintenance, allocates shortage risk equitably, and is agreed upon in a transparent manner between all members of the irrigation system (Dayton-Johnson 2000, Torell and Ward 2010, Bernard et al. 2013, Ward et al. 2013). However, the present study draws a contrasting finding; shortage sharing can actually result in worse performance overall, and for tail-end users in particular, if rotation is not also employed. However the present study finds that shortage sharing produces benefits overall when coupled with rotational delivery.

As for rotation, the literature has largely found that rotation accomplishes the goals it is implemented to achieve: it improves equality between the head-end and tail-end (Turral et al. 2002, Abdullaev et al. 2006). Indeed, irrigators in the SLV directly stated in interviews that this was the intention of rotation. Although Janssen et al. (2012) did not make this finding in an experimental setting, the rotational delivery mechanism was not accompanied by enforcement of any maximum diversion duration or amount, was not negotiated by the irrigators, and the effect of rotation was not the focus of the study. Additionally, rotation was selected by $2 / 3$ of the experimental groups of real-world irrigators in Janssen 
Fig. 6. Marginal productivity of water at different distances from the diversion. Each panel illustrates the relationship between volume diverted per unit area and Normalized Difference Vegetation Index (NDVI) for a different value of field distance from diversion, representing 5, 50, and $95 \%$, respectively, of the maximum field distance of its irrigation system. This corresponds to head-enders, mid-reachers, and tail-enders. SDNS = Simultaneous Delivery with No Sharing; RNS $=$ Rotation with No Sharing; SDS $=$ Simultaneous Delivery and Sharing; RS $=$ Rotation and Sharing; SOLE $=$ Sole User. Confidence bands are at $90 \%$.

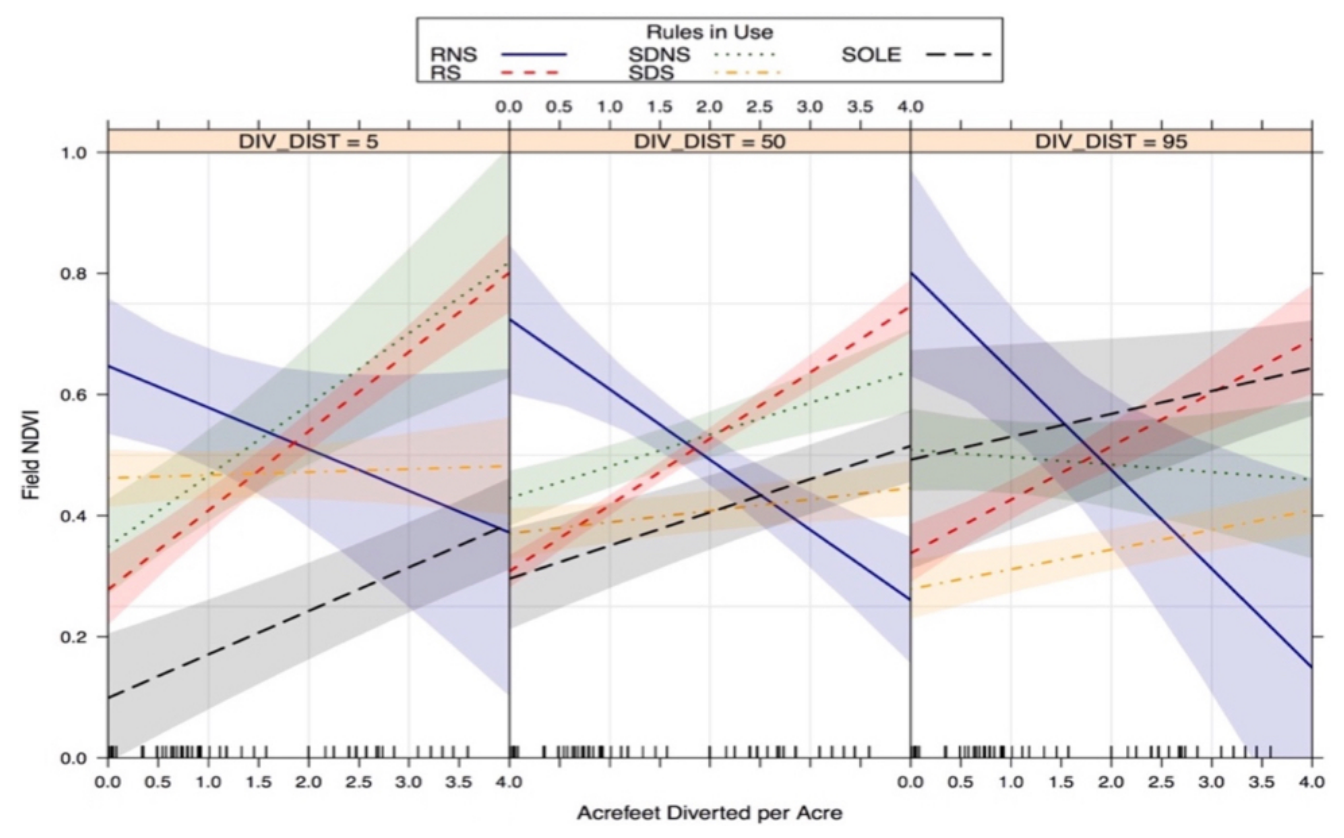

et al. (2012), possibly because irrigators understand that rotation is effective and equitable. Similar to other studies, the findings of the present study do not find that rotation is necessarily efficiency enhancing, only that under a well-functioning rotational system the most vulnerable irrigators, i.e., tail-enders, are spared from the worse consequences of drought, particularly when shortage sharing is also allowed.

The fundamental contribution of this study is that the effects of delivery and allocation rules differ depending on their configuration. Baggio et al. (2016) found configurations important when looking at the design principles offered by Ostrom (2005), however this study finds configurations important for specific operational rules in use. Indeed, the impact of the same combinations of delivery and shortage sharing rules can differ between head-enders and tail-enders, and even these effects are conditional on the degree of water shortage.

The policy implications of these findings are not prescriptive. The answer to the question, "Which rule is best?" depends on which other rules are in place. The answer to the derivative question, "Which configuration of rules is best?" also depends a great deal on where the farmer asking the question is located on the irrigation system and how much water is available to that system. Therefore, water managers and irrigators alike should weigh hydrologic context, equity, and social norms heavily in determining which rules to experiment with and adopt.

\section{CONCLUSION}

Optimality depends strongly on normative assessments of equity (Ingram et al. 2008). This study implies that the optimal choice of institutions depends strongly on the normative, infrastructural, and hydrologic conditions of a given irrigation system over a period of many years. These findings have implications for an era of climate change, wherein irrigated agriculture will face serious challenges (Turral et al. 2011, FAO 2012, Lee et al. 2014, Kramer et al. 2017) and institutional changes have been proposed as potential adaptations (Huntjens et al. 2012). Moreover, the highly contextual influence of the rules in use under investigation highlight the configurational relationships between rules in use (Baggio et al. 2016), further demonstrate institutional interactions with biophysical context (Cody 2018), caution against panaceas in water resource management (Meinzen-Dick 2007), and support a diagnostic approach to institutional analysis (Ostrom 2007). Because of the delicate distribution of individual and group costs and benefits (Bell et al. 2016, Pérez, et al. 2016, McCord et al. 2017), heterogeneous market integration (Kininmonth et al. 2016); and divergent hydrology, infrastructure, ecological context, and institutions, "Institutional change needs to be seen as an organic process, building on existing norms and practices, rather than as an exercise in social engineering" (Meinzen-Dick 2014:23).

That said, this study shows rotational delivery with shortage sharing as the most robust institutional configuration examined. In addition to generating the most equality between head-enders 
and tail-enders overall, this configuration has positive marginal productivity up and down the canal at all levels of water availability, and therefore represents a safe bet under uncertain water supplies. This configuration also appears to be well suited for systems large and small, growing a wide array of crops, with different social and cultural norms, and various technological and infrastructural mixes. However, it does require sufficient resources and labor to engage in the necessary negotiations, monitoring, and, presumably, sanctioning. It may also have some hydrologic and agronomic limitations in severe shortage, with water being spread too thinly. Perhaps this is why, in the Hispanic acequia tradition in the SLV where rotation and shortage sharing were traditionally practiced, extreme shortage was met by growing crops on only the best land, with the surplusses shared among the community. That said, there are limitations to this study, and so future work should include direct measures of welfare, identify farm units, use simulations, and investigate different water rights and climatic regimes.

Responses to this article can be read online at: http://www.ecologyandsociety.org/issues/responses. php/10193

\section{Acknowledgments:}

This study would not have been possible without funding from National Science Foundation grant BCS-1115009, the Colorado Section of the American Water Resources Association, and the Arkansas River Basin Water Forum. Publication of this article was funded by the University of Colorado Boulder Libraries Open Access Fund. All human subjects research conducted in compliance with CU IRB protocol \#13-0181. The author thanks Krister Andersson, Steven Smith, Michael Cox, Kyle Kittelberger, and Matt Foster for their help collecting and coding the data. The author thanks Krister Andersson, Steven Smith, Tanya Heikkila, Doug Kenney, Lisa Dilling, Michael Cox, John Wiener, Nathan LeeAmmons, Robert Patrie, Bill Cody, Dara Hill, and Lisette Arellano for their constructive input and support. Several anonymous reviewers also provided valuable advice. Last but not least, the author also thanks the farmers and water managers in the San Luis Valley for their time, especially members of the Rio Grande Basin Roundtable and the staff of the State Engineer's Office. All remaining errors are the author's.

\section{LITERATURE CITED}

Abdullaev, I., M. U. I. Hassan, H. Manthrithilake, and M. Yakubov. 2006. The reliability improvement in irrigation services: application of rotational water distribution to tertiary canals in Central Asia. IWMI Research Report 100. International Water Management Institute, Colombo, Sri Lanka. [online] URL: http://www.iwmi.cgiar.org/Publications/IWMI_Research_Reports/ PDF/pub100/RR100.pdf

Arnold, T. C. 2008. The San Luis Valley and the moral economy of water. Pages 37-67 in J. M. Whitely, H. Ingram, and R. W. Perry, editors. Water, place, and equity. MIT Press, Cambridge, Massachusetts, USA. http://dx.doi.org/10.7551/mitpress/97802$\underline{62232715.003 .0002}$
Baggio, J. A., A. J. Barnett, I. Pérez-Ibara, U. Brady, E. Ratajczyk, N. Rollins, C. Rubiños, H. C. Shin, D. J. Yu, R. Aggarwal, J. M. Anderies, and M. A. Janssen. 2016. Explaining success and failure in the commons: the configural nature of Ostrom's institutional design principles. International Journal of the Commons. 10 (2):417-439. http://dx.doi.org/10.18352/ijc.634

Bell, A. R., P. S. Ward, and M. A. A. Shah. 2016. Increased water charges improve efficiency and equity in an irrigation system. Ecology and Society 21(3):23. http://dx.doi.org/10.5751/ ES-08642-210323

Bernard, M., A. Dreber, P. Strimling, and K. Eriksson. 2013. The subgroup problem: when can binding voting on extractions from a common pool resource overcome the tragedy of the commons? Journal of Economic Behavior and Organization 91:122-130 http:// dx.doi.org/10.1016/j.jebo.2013.04.009

Bivand, R., and G. Piras. 2015. Comparing implementations of estimation methods for spatial econometrics. Journal of Statistical Software 63(18):1-36. http://dx.doi.org/10.18637/jss. v063.i18

Cifdaloz, O., A. Regmi, J. M. Anderies, and A. A. Rodriguez. 2010. Robustness, vulnerability, and adaptive capacity in smallscale social ecological systems: the pumpa irrigation system in Nepal. Ecology and Society 15(3):39. http://dx.doi.org/10.5751/ ES-03462-150339

Cody, K. 2018. Upstream with a shovel or downstream with a water right? Irrigation in a changing climate. Environmental Science and Policy 80:62-73. http://dx.doi.org/10.1016/j. envsci.2017.11.010

Cody, K., S. M. Smith, M. Cox, and K. Andersson. 2015. Emergence of collective action in a groundwater commons: irrigators in the San Luis Valley of Colorado. Society and Natural Resources 28(4):405-422. http://dx.doi.org/10.1080/08941920.2014.970736

Colorado Climate Center (CCC). N.D. Drought resources: Q and A about drought. Colorado Climate Center, Colorado State University, Fort Collins, Colorado, USA. [online] URL: $\underline{\text { http:// }}$ ccc2.atmos.colostate.edu/droughtqanda.php Put in the text

Colorado Division of Water Resources. N.D. Division 3 (Alamosa): Rio Grande River Basin. Accessed Nov 5, 2016: http://water.state.co.us/DivisionsOffices/Div3RioGrandeRiverBasin/ Pages/Div3RioGrandeRB.aspx

Cox, M. 2010. Exploring the dynamics of social-ecological systems: the case of the Taos Valley Acequias. Dissertation. Indiana University, Bloomington, Indiana, USA. [online] URL: http://dlc.dlib.indiana.edu/dlc/bitstream/handle/10535/5637/Cox $\%$ 20dissertation.pdf

Cox, M. 2014. Modern disturbances to a long-lasting communitybased resource management system: the Taos Valley Acequias. Global Environmental Change 24:213-222. http://dx.doi. org/10.1016/j.gloenvcha.2013.12.006

Cox, M. 2015. A basic guide for empirical environmental social science. Ecology and Society 20(1):63. http://dx.doi.org/10.5751/ ES-07400-200163

Cox, M., and J. M. Ross. 2011. Robustness and vulnerability of community irrigation systems: the case of the Taos Valley Acequias. Journal of Environmental Economics and Management 61(3):254-266. http://dx.doi.org/10.1016/j.jeem.2010.10.004 
Dayton-Johnson, J. 2000. Choosing rules to govern the commons: a model with evidence from Mexico. Journal of Economic Behavior and Organization 42(1):19-41. http://dx.doi.org/10.1016/S0167-2681 (00)00073-1

Deryng, D., J. Elliott, C. Folberth, C. Müller, T. A. M. Pugh, K. J. Boote, D. Conway, A. C. Ruane, D. Gerten, J. W. Jones, N. Khabarov, S. Olin, S. Schaphoff, E. Schmid, H. Yang, and C. Rosenzweig. 2016. Regional disparities in the beneficial effects of rising $\mathrm{CO} 2$ concentrations on crop water productivity. Nature Climate Change 6(8):786-790. http://dx.doi.org/10.1038/nclimate2995

D'Exelle, B., E. Lecoutere, and B. Van Campenhout. 2012. Equity-efficiency trade-offs in irrigation water sharing: evidence from a field lab in Rural Tanzania. World Development 40 (12):2537-2551. http://dx.doi.org/10.1016/j.worlddev.2012.05.026

Dinar, A., M. W. Rosegrant, and R. Meinzen-Dick. 1997. Water allocation mechanisms: principles and examples. Policy research working paper no. WPS 1779. World Bank, Washington, D.C., USA. [online] URL: http://documents.worldbank.org/curated/ en/640941468766210195/pdf/multi-page.pdf http://dx.doi. org/10.1596/1813-9450-1779

Food and Agriculture Organization of the United Nations (FAO). 2012. The state of food insecurity in the world. Food and Agriculture Organization of the United Nations, Rome, Italy. http://www.fao.org/docrep/016/i3027e/i3027e.pdf

Gleick, P. H. 2003. Global freshwater resources: soft-path solutions for the 21st century. Science 302(5650):1524-1528. http://dx.doi.org/10.1126/science.1089967

Gujarati, D. N., and D. C. Porter. 2009. Basic econometrics. McGraw-Hill, New York, New York, USA.

He, L., T. M. Horbulyk, M. K. Ali, D. G. Le Roy, and K. K. Klein. 2012. Proportional water sharing vs. seniority-based allocation in the Bow River basin of Southern Alberta. Agricultural Water Management 104:21-31. http://dx.doi.org/10.1016/j.agwat.2011.11.008

Huntjens, P., L. Lebel, C. Pahl-Wostl, J. Camkin, R. Schulze, and N. Kranz. 2012. Institutional design propositions for the governance of adaptation to climate change in the water sector. Global Environmental Change 22:67-81. http://dx.doi.org/10.1016/ j.gloenvcha.2011.09.015

Ingram, H., J. M. Whiteley, and R. Perry. 2008. The importance of equity and the limits of efficiency in water resources. Pages 1-32 in J. M. Whitely, H. Ingram, and R. W. Perry, editors. Water, place, and equity. MIT Press, Cambridge, Massachusetts, USA. http://dx.doi.org/10.7551/mitpress/9780262232715.003.0001

Janssen, M. A., J. M. Anderies, and J.-C. Cardenas. 2011. Headenders as stationary bandits in asymmetric commons: comparing irrigation experiments in the laboratory and the field. Ecological Economics 70(9):1590-1598. http://dx.doi.org/10.1016/j. ecolecon.2011.01.006

Janssen, M. A., F. Bousquet, J.-C. Cardenas, D. Castillo, and K. Worrapimphong. 2012. Field experiments on irrigation dilemmas. Agricultural Systems 109:65-75. http://dx.doi.org/10.1016/j. agsy.2012.03.004

Joshi, N. N., E. Ostrom, G. P. Shivakoti, and W. F. Lam. 1998. An institutional analysis of the effects of different modes of assistance on the performance of farmer-managed irrigation systems in Nepal. 7th Conference of the International Association for the Study of Common Property, June 10-14, 1998, Vancouver, British Columbia, Canada. Indiana University, Bloomington, Indiana, USA. [online] URL: https://dlc.dlib.indiana.edu/dlc/ bitstream $/$ handle $/ 10535 / 2163 /$ joshi.pdf? sequence $=1 \&$ isAllowed $=$ y

Kenney, D. 2005. Prior appropriation and water rights reform in the Western United States. Pages 167-182 in B. R. Bruns, C. Ringler, and R. S. Meinzen-Dick, editors. Water rights reform: lessons for institutional design. International Food Policy Research Institute, Washington, D.C., USA. http://dx.doi. org/10.2499/0896297497.Ch7

Kininmonth, S., B. Crona, Ö. Bodin, I. Vaccaro, L. J. Chapman, and C. A. Chapman. 2016. Microeconomic relationships between and among fishers and traders influence the ability to respond to social-ecological changes in a small-scale fishery. Ecology and Society 22(2):26. http://dx.doi.org/10.5751/ES-08833-220226

Koirala, S., Y. Hirabayashi, R. Mehendran, and S. Kanea. 2014. Global assessment of agreement among streamflow projections using CMIP5 model outputs. Environmental Research Letters 9 (6). http://dx.doi.org/10.1088/1748-9326/9/6/064017

Kramer, D. B., J. Hartter, A. E. Boag, M. Jain, K. Stevens, K. A. Nicholas, W. J. McConnell, and J. Liu. 2017. Top 40 questions in coupled human and natural systems (CHANS) research. Ecology and Society 22(2):44. http://dx.doi.org/10.5751/ES-09429-220244

Lam, W. F. 1998. Governing irrigation systems in Nepal: institutions, infrastructure, and collective action. Institute for Contemporary Studies, Oakland, California, USA.

Lee, D. R., S. Edmeades, E. De Nys, A. McDonald, and W. Janssen. 2014. Developing local adaptation strategies for climate change in agriculture: a priority-setting approach with application to Latin America. Global Environmental Change 29:78-91. http://dx.doi.org/10.1016/j.gloenvcha.2014.08.002

Llewellyn, D., and S. Vaddey. 2013. West-wide climate risk assessment: Upper Rio Grande impact assessment. U.S. Department of the Interior, Bureau of Reclamation, Upper Colorado Region, Albuquerque Area Office, Albuquerque, New Mexico, USA.

Lukas, J., J. Barsugli, J. Doesken, I. Rangwala, and K. Wolter. 2014. Climate change in Colorado: a synthesis to support water resources management and adaptation. A report for the Colorado Water Conservation Board. Western Water Assessment, Boulder, Colorado, USA. [online] URL: http://wwa.colorado.edu/climate/ co2014report/Climate Change CO Report 2014 FINAL.pdf

Mabry, J. B. 1996. Canals and communities: small-scale irrigation systems. University of Arizona Press, Tucson, Arizona, USA.

McCord, P., J. Dell'Angelo, D. Gower, K. Caylor, and T. Evans. 2017. Household-level heterogeneity of water resources within common-pool resource systems. Ecology and Society 22(1):48. http://dx.doi.org/10.5751/ES-09156-220148

Meinzen-Dick, R. 2007. Beyond panaceas in water institutions. Proceedings of the National Academy of Sciences 104 (39):15200-15205. http://dx.doi.org/10.1073/pnas.0702296104 
Meinzen-Dick, R. 2014. Property rights and sustainable irrigation: a developing country perspective. Agricultural Water Management 145:23-31. http://dx.doi.org/10.1016/j.agwat.2014.03.017

Mix, K., V. L. Lopes, and W. Rast. 2011. Annual and growing season temperature changes in the San Luis Valley, Colorado. Water Air Soil Pollution 220(1):189-203. http://dx.doi. org/10.1007/s11270-011-0746-4

Mix, K., V. L. Lopes, and W. Rast. 2012. Growing season expansion and related changes in monthly temperature and growing degree days in the inter-montane desert of the San Luis Valley, Colorado. Climatic Change 114(3-4):723-744. http://dx. doi.org/10.1007/s10584-012-0448-y

North, D. C. 1990. Institutions, institutional change and economic performance: political economy of institutions and decisions. Cambridge University Press, Cambridge, UK. http://dx.doi. org/10.1017/CBO9780511808678

Ostrom, E. 1992. Crafting institutions for user-governing irrigation systems. Institute of Contemporary Studies, Oakland, California, USA.

Ostrom, E. 2005. Understanding institutional diversity. Princeton University Press, Princeton, New Jersey, USA.

Ostrom, E. 2007. A diagnostic approach for going beyond panaceas. Proceedings of the National Academy of Sciences 104 (39):15181-15187. http://dx.doi.org/10.1073/pnas.0702288104

Ostrom, E. 2014. Do institutions for collective action evolve? Journal of Bioeconomics 16(1):3-30. http://dx.doi.org/10.1007/ s10818-013-9154-8

Pérez, I., M. A. Janssen, and J. M. Anderies. 2016. Food security in the face of climate change: adaptive capacity of small-scale social-ecological systems to environmental variability. Global Environmental Change 40:82-91. http://dx.doi.org/10.1016/j. gloenvcha.2016.07.005

Poteete, A. R., M. A. Janssen, and E. Ostrom. 2010. Working together: collective action, the commons, and multiple methods in practice. Princeton University Press, Princeton, New Jersey, USA. http://dx.doi.org/10.1515/9781400835157

Primo, D. M., M. L. Jacobsmeier, and J. Milyo. 2007. Estimating the impact of state policies and institutions with mixed-level data. State Politics and Policy Quarterly 7(4):446-459. http://dx.doi. org/10.1177/153244000700700405

R Core Team. 2015. R: a language and environment for statistical computing. Version 3.2.2. R Foundation for Statistical Computing, Vienna, Austria. [online] URL: https://cran.rproject.org/bin/windows/base/old/3.2.2/

Rivera, J. A. 1998. Acequia culture: water, land, and community in the Southwest. University of New Mexico Press, Albuquerque, New Mexico, USA.

Rodriguez, S. 2006. Acequia: water sharing, sanctity, and place. School for Advanced Research Press, Santa Fe, New Mexico, USA.

Sax, J. L., B. H. Thompson, Jr., J. D. Leshy, and R. H. Abrams. 2006. Sax, Thompson, Leshy and Abrams' legal control of water resources. Fourth edition. West Publishing, St. Paul, Minnesota, USA.

Smith, S. M. 2016. Common property resources and new entrants: uncovering the bias and effects of new users. Journal of the Association of Environmental and Resource Economists 3(1):1-36. http://dx.doi.org/10.1086/683683

Torell, G. L., and F. A. Ward. 2010. Improved water institutions for food security and rural livelihoods in Afghanistan's Balkh River Basin. International Journal of Water Resources Development 26(4):613-637. http://dx.doi.org/10.1080/07900627.2010 .519492

Turral, H., H. Malano, and N. V. Chien. 2002. Development and specification of a service agreement and operational rules for $\mathrm{La}$ Khe irrigation system, Ha Dong, Vietnam. Irrigation and Drainage 51(2):129-140. http://dx.doi.org/10.1002/ird.48

Turral, H., J. Burke, and J. M. Faurés. 2011. Climate change, water and food security. Food and Agriculture Organization of the United Nations, Rome, Italy. [online] URL: http://www.fao.org/ docrep/014/i2096e/i2096e.pdf

United Nations Educational, Scientific, and Cultural Organization (UNESCO). 2012. Facts and figures from the United Nations world water development report 4. United Nations World Water Assessment Program, Perugia, Italy.

United States Department of Agriculture (USDA). 2014. Land use on farms with irrigation: 2013 and 2008. United States Department of Agriculture, Washington, D.C., USA. https:// www.agcensus.usda.gov/Publications/2012/Online Resources/ Farm and Ranch Irrigation Survey/fris13 1003 003.pdf

Vicuña, S., J. McPhee, and R. D. Garreaud. 2012. Agriculture vulnerability to climate change in a snowmelt-driven basin in semiarid Chile. Journal of Water Resources Planning and Management 138(5):431-441. http://dx.doi.org/10.1061/(ASCE) WR.1943-5452.0000202

Villamayor-Tomas, S. 2012. Robustness to droughts in a multilevel governance irrigation systems: a statistical analysis of Riegos del Alto Aragon irrigation systems. in Design and dynamics of institutions for collective action, Nov. 29 - Dec. 1 2012. Utretch University, Utretch, The Netherlands.

Ward, F. A., S. A. Amer, and F. Ziaee. 2013. Water allocation rules in Afghanistan for improved food security. Food Security 5 (1):35-53. http://dx.doi.org/10.1007/s12571-012-0224-x

Wheeler, T., and J. von Braun. 2013. Climate change impacts on global food security. Science 341(6145):508-513. http://dx.doi. org/10.1126/science. 1239402

Wiltshire, A., J. Gornall, B. Booth, E. Dennis, P. Falloon, G. Kay, D. McNeall, C. McSweeney, and R. Betts. 2013. The importance of population, climate change and $\mathrm{CO}_{2}$ plant physiological forcing in determining future global water stress. Global Environmental Change 23:1083-1097. http://dx.doi.org/10.1016/j. gloenvcha.2013.06.005 


\section{APPENDIX 1}

\section{STUDY AREA DESCRIPTION}

\section{Geographic description}

The San Luis Valley of Colorado is a high-altitude desert, 7,000 feet above sea level, where a rural community of about 50,000 irrigates 400,000-500,000 acres using snowmelt from the surrounding Rocky Mountains. The valley receives little rain, just 7-10 inches annually, making irrigation necessary for agriculture. The economy of the SLV depends almost entirely on irrigated agriculture, and for many of the people there the struggle to grow crops is existential. Because the SLV is a headwaters system, because there is no major urban center to demand water in the Rio Grande basin in Colorado, and because major trans-mountain exports have been made prohibitively expensive by geography and local opposition (Cody et al., 2015), the dynamics of agricultural systems can be explored alone, without the confounding factors introduced by significant urban and industrial users of water competing with agriculture and upstream use dynamics.

\section{Irrigation system, field, and year attributes}

The study area consists of approximately 700 active self-governing irrigation systems. A stratified sample of 60 systems was collected in the Summer of 2013. Of the 60 sampled, systems irrigate anywhere from 30 to over 115,000 acres and have between 1 and over 300 irrigators. Major crops grown include alfalfa, grass pasture, small grains, potatoes, and other minor crops such as vegetables. Fields themselves range in size from less than an acre to over 750 acres. The study runs from 2011-2014, a period of well below average stream flow (Table 1). The years 2011, 2012, and 2014 are included as robustness checks; the rules being analyzed were assessed in 2013, and are assumed to have been in place in 2011, 2012, and 2014. See Table 7 for an overview of the variables included in the analysis. See Table 1 for a summary of the key independent variables used in the analysis across the years of the study broken out by the institutional configurations under consideration. See Figure 1 for a color-coded map of the irrigation systems sampled and their institutional configurations.

Table 1. Summary of independent variables of interest for each institutional configuration.

\begin{tabular}{llllllll}
\hline Institutional Group & $\begin{array}{l}\text { Total } \\
\text { Sampled }\end{array}$ & $\begin{array}{l}\text { Ave. } \\
\text { Max. } \\
\text { Dist. } \\
(\mathrm{km})\end{array}$ & $\begin{array}{l}\text { Ave. } \\
\text { AF/Acre }\end{array}$ & $\begin{array}{l}\text { Ave. } \\
\text { AF/Acre } \\
2011\end{array}$ & $\begin{array}{l}\text { Ave. } \\
\text { AF/Acre }\end{array}$ & $\begin{array}{l}\text { Ave. } \\
\text { AF/Acre } \\
2012\end{array}$ & $\begin{array}{l}\text { Ave. } \\
\text { AF/Acre } \\
2011- \\
2014\end{array}$ \\
\hline $\begin{array}{l}\text { Simultaneous, Not } \\
\text { Sharing }\end{array}$ & 13 & 9.687 & 1.943 & 1.753 & 1.873 & 2.060 & 1.91 \\
$\begin{array}{l}\text { Simultaneous, } \\
\text { Sharing }\end{array}$ & 11 & 17.037 & 3.209 & 1.905 & 1.855 & 3.762 & 2.68 \\
$\begin{array}{l}\text { Rotation, Not } \\
\begin{array}{l}\text { Sharing } \\
\text { Rotation, Sharing }\end{array}\end{array}$ & 8 & 6.739 & 1.054 & 1.166 & 0.870 & 1.753 & 1.21 \\
Overall & 28 & 10.879 & 1.769 & 1.736 & 2.021 & 3.026 & 2.14 \\
\hline
\end{tabular}


Figure 1. A simple map of the sampled irrigation systems, color-coded for their institutional configuration.

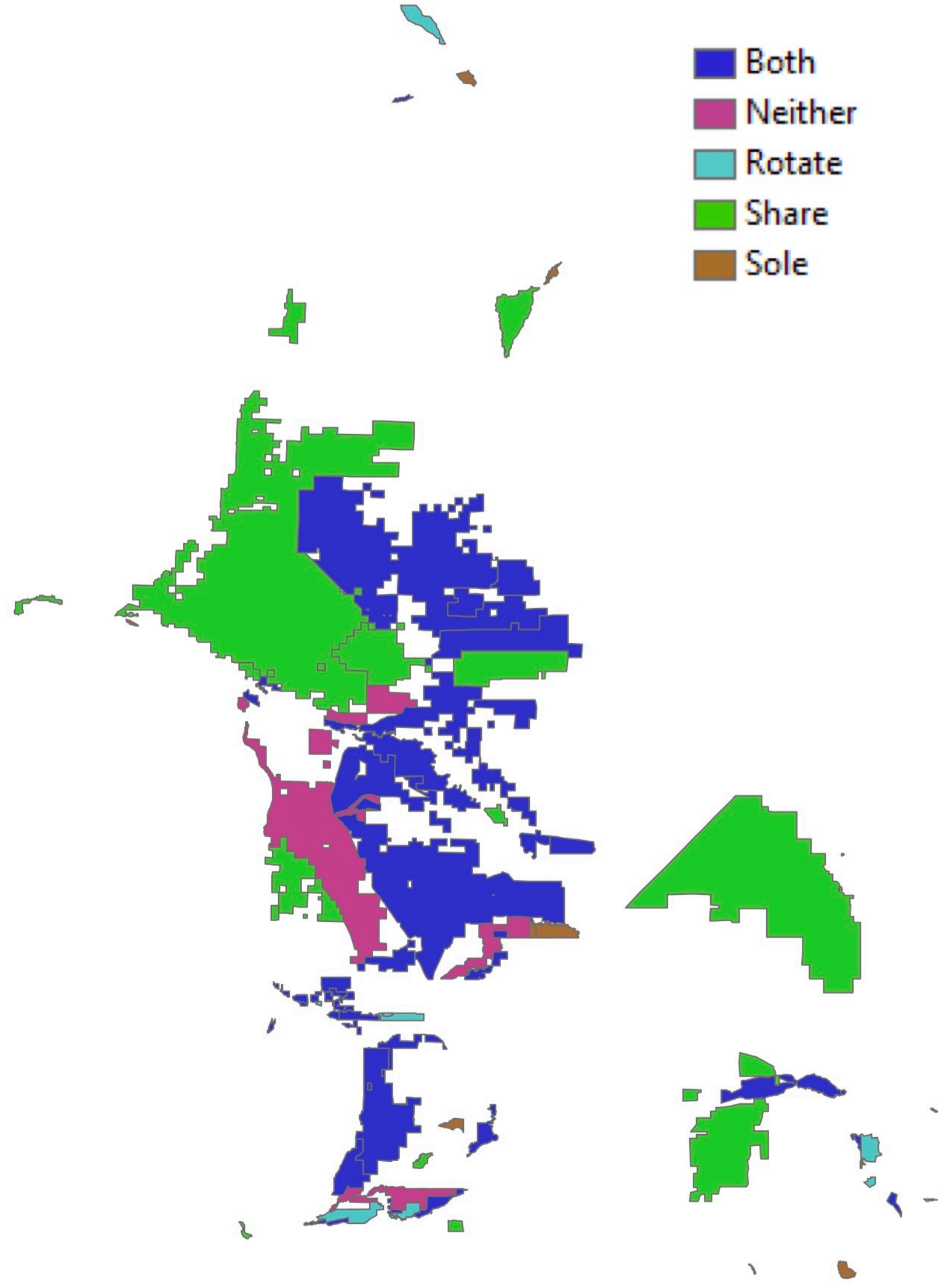




\section{Long-term climate change in the SLV}

Spring snowpack is expected to decline across Colorado due to climate change, with decreasing stream flow in the Rio Grande basin especially (Lukas et al., 2014). Indeed, there have already been observed changes in temperature, and therefore frost-free season and onset of peak stream flow that warrant an investigation in Colorado's Rio Grande Basin (Lukas et al., 2014; Mix et al., 2009; Mix et al., 2011; Mix et al., 2012). USGS streamflow data going back to the 1880s on the Rio Grande do show longer term decreases in accordance with expectations of climate change. In addition to the studies by Mix et al. $(2009,2011,2012)$ on growing degree days, temperature, and runoff at the Lobatos gage on the New Mexico state line, runoff data exists going back to the 1890 on the Rio Grande in Colorado above any major diversions at the gage at Del Norte (also the gage which determines Rio Grande Compact obligations).

Because the major focus of this investigation is irrigation performance under climate change, and because the SLV is snowmelt limited, it is important to establish variability of snowpack and an overall declining trend.

Figure 2. Annual mean temperature and snowpack from 1984-2015 of all stations with at least 15 years of data.
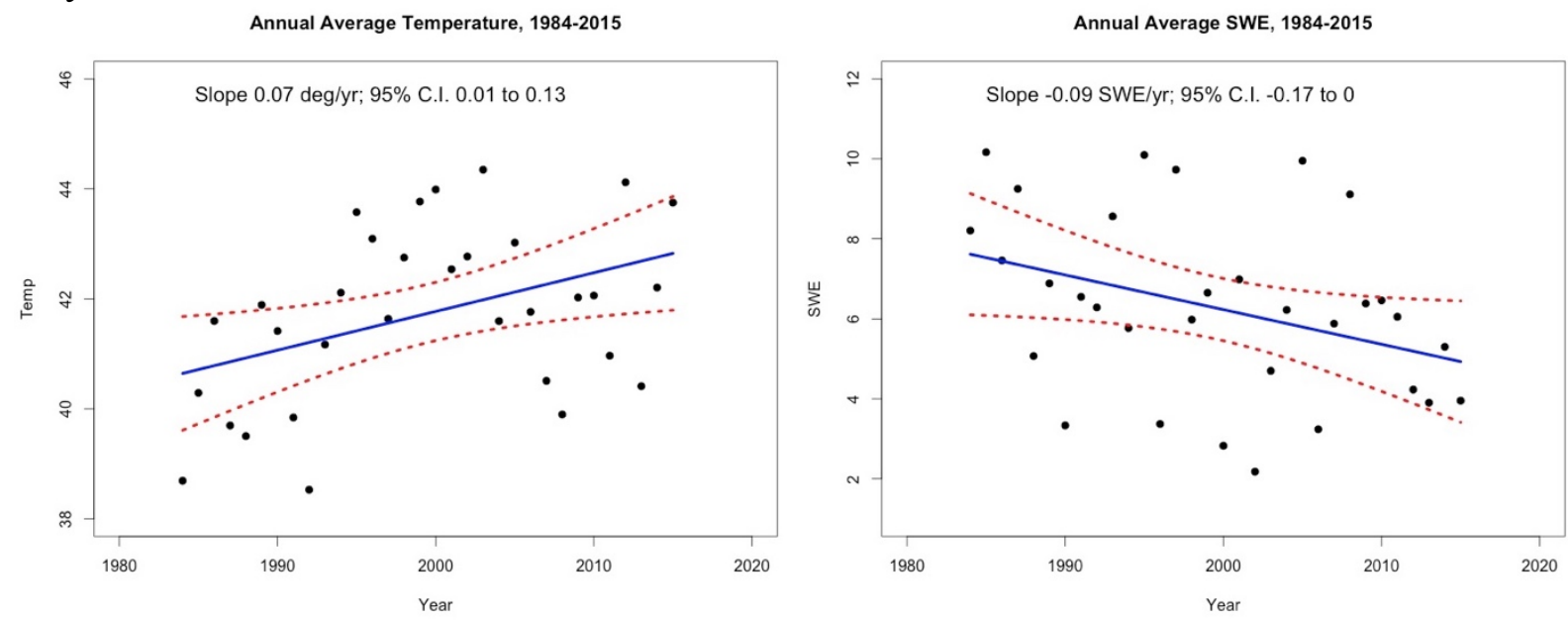

To establish the validity of the recent past as analogous to expectations under climate change, Figure 2 depicts the annual variability of snowpack and temperature in the study area with regression trend lines. Because the slopes in these figures depend on when the time-series starts and stops, they should not be interpreted as indicating climate change per se, but as evidence that the recent past is analogous to expected climate change. During the study period, 2011-2014, snowpack has been well below normal, as illustrated by Figure 3 and Table 2 .

Figure 3. Snowpack in the SLV from 2011-2014, showing below normal volume, earlier peak, and earlier melt. From: https://www.nrcs.usda.gov/wps/portal/nrcs/detail/co/snow/products/?cid=nrcs144p2 063323 


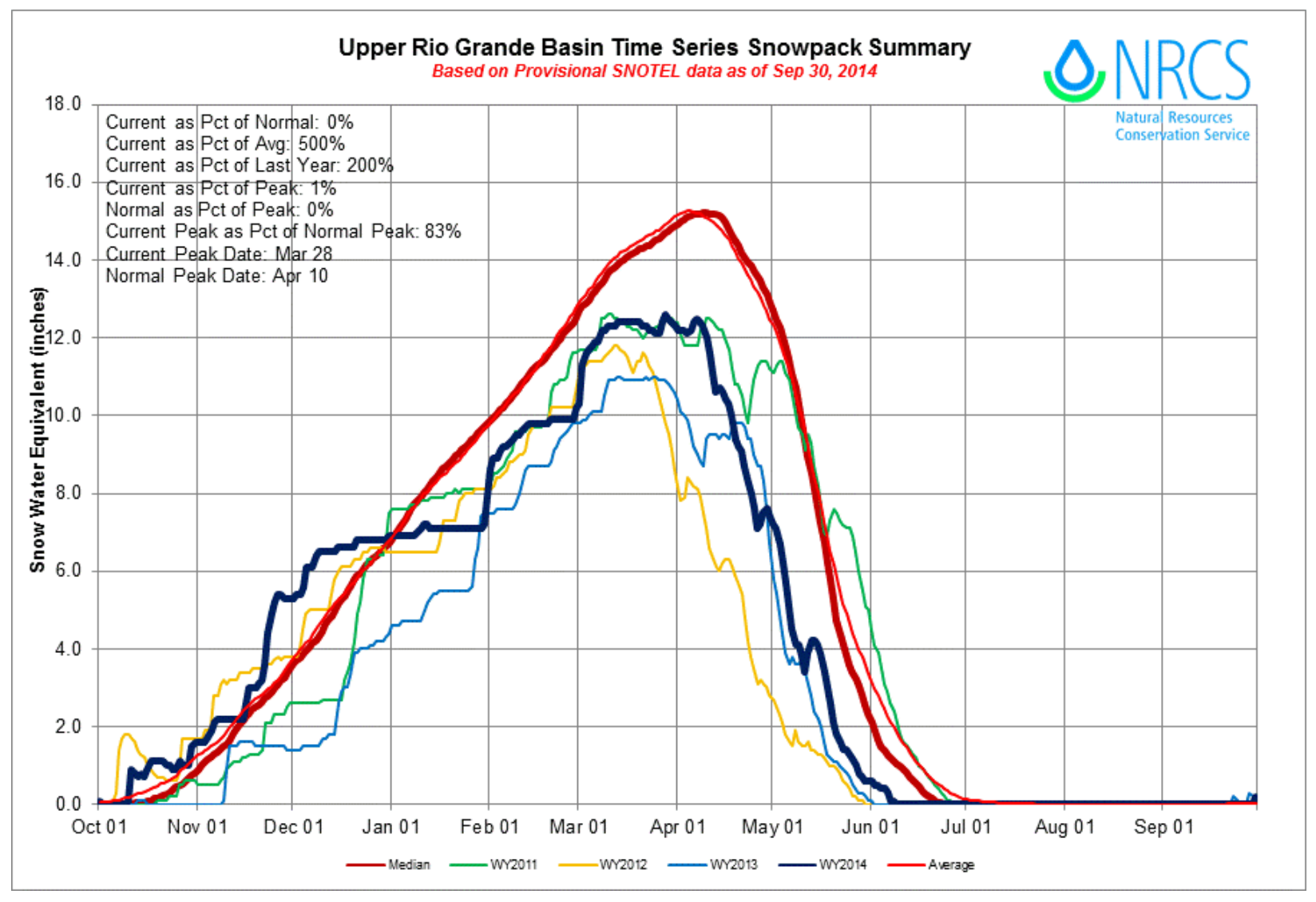

Data from the 1880s to the present show a decrease in streamflow on the Rio Grande. Changes in temperature, frost-free season, growing degree days, and onset of peak stream flow have already been observed in the SLV (Mix et al., 2011; Mix et al., 2012), These changes call for an investigation into the effects of climate change on irrigated agriculture in the SLV. Important for this analysis, streamflow at the nearest upstream gages of the self-governing irrigation systems that were sampled was well below average in the years 2011-2013, with 2014 being slightly below average.

Table 2. Summary of the irrigation seasons analyzed, showing that snowpack, streamflow, and percentage of acreage irrigated were below average in each year.

\begin{tabular}{|c|c|c|c|c|}
\hline Irrigation Conditions and Outcomes & 2011 & 2012 & 2013 & 2014 \\
\hline Percent of Average Snow Water Equivalent & 96.5 & 67.5 & 62.2 & 84.5 \\
\hline Average of Upstream Gages Percent of Average & 66.1 & 56.6 & 48.5 & 83.9 \\
\hline Average Months of Active Diversion & 4.13 & 4.08 & 4.47 & 4.88 \\
\hline Average Percent Maximum Diversion & 39.5 & 35.5 & 35.8 & 52.3 \\
\hline Average Acre-feet Diverted per Acre & 1.98 & 1.69 & 1.80 & 2.77 \\
\hline Average Percent Acres Irrigated & 62.3 & 57.2 & 62.2 & 74.1 \\
\hline
\end{tabular}

2. WATER RIGHTS, RULES IN USE, AND CLIMTE CHANGE ADAPTATION 
Adapting irrigated agriculture to climate change in the SLV and elsewhere will be contextually dependent on the incumbent water rights regime. In the SLV, this regime is known as Prior Appropriation (PA) (Adler, 2010; Kenney, 2005). PA is the dominant or exclusive regime of water allocation in Colorado, the rest of the Western United States, Australia, and Western Canada. It is generally inflexible during shortage (Howe et al., 1982), with the exception that it is possible (though costly and slow) to sell or lease water rights. Under Colorado's version of this system, water right holders are ranked on a priority list determined by the order in which their water rights were adjudicated by the state's Water Court; this is often summarized as "first in time, first in right". When there is not enough water available to satisfy all water right holders, entities with the most recent ("junior") rights, are curtailed or denied water entirely so that those with the oldest and therefore most "senior" rights can divert their full allocation. In practice, this means that senior users are able to divert their full right for longer periods of time than junior users, who may be limited to a matter of days or weeks or receive no water at all. This poses significant challenges for all except the most senior water rights holders during drought. Thus, in the SLV, although the weather-induced shortage that different irrigation systems experience may be similar in a given year, they experience different levels of legal water shortage.

Prior Appropriation creates persistent inequalities between irrigation systems. Over time PA leads to the failure of farms on junior systems and consolidation of ownership, where farmers on senior ditch systems buy land and water rights on junior ones. And while this is a profitable system for seniors, it discourages efficiency by senior users who are guaranteed their full allocation, leading to lost potential profits throughout the system. A strict application of the PA system also discourages the highest marginal return on water use by depriving juniors of the ability to farm entirely so that seniors can improve crop vigor (Howe et al., 1982). Unique return flow dynamics can lead to externalities when transfers occur in water markets (Howe et al., 1982). In addition, PA has no inherent place for environmental uses of water, posing challenges for ecosystem integrity under a water constrained future; only in the past 40 to 20 years have in stream flows and non-consumptive recreational uses been incorporated into Colorado water law. Prior Appropriation may therefore be working against risk mitigation and may exacerbate inequalities and vulnerabilities in the overall agricultural sector. However, because of the strong vested interests and legal framework surrounding PA, it is unlikely to be meaningfully altered.

The unique features of PA aside, other water rights regimes in operation around the world also produce differential outcomes (Dinar, et al., 1997). In drought, some if not all irrigation systems inevitably divert less water than they normally would. Climate change will exacerbate this by challenging established institutional arrangements. Existing centralized adaptive management regimes may be too slow to respond to the pace of change and increase in variability. New institutional arrangements may be needed in order to imbed more rapid adaptations at local and regional levels that respond to change independent from central governing authorities. Even in a developed economy in a state with secure property rights to water, self-governed irrigation systems are challenged to adapt to their changing environments (Cox, 2014; Fernald et al., 2012), and these challenges result in varying irrigation performance (Cox \& Ross, 2011; Janssen \& Anderies, 2013). Are there micro-level institutions, i.e. rules in use adopted by irrigators which limit behavior under threat of sanction (Ostrom, 1990), that irrigators can design among themselves that may mitigate against the risks associated with climate change and an externally enforced, relatively inflexible, and harsh private property rights regime? Put another way, how 
do different institutional configurations adopted by self-governing irrigation systems influence irrigation performance in drought?

This paper argues that self-governance can be used to improve irrigation performance during drought. Micro-institutions are some of the few things irrigators can control beyond their land, and so they are vital as a first response to drought. Other potential changes are more expensive and disruptive to implement. Cultural norms are resistant to change and evolve slowly (Poteete et al., 2010). Technological and infrastructural changes are expensive and can have unintended consequences (Lam, 1998). Legislative changes, such as those to an incumbent water rights regime, usually challenge powerful vested interests, may be too general, and often have effects that go beyond what is intended (Ostrom, 2005). In contrast, user-originated rules in use are less expensive to change, voluntarily adopted, tailored to local conditions and norms, and relatively reversible. These rules in use affect users' economic incentives and signal to users the relative social costs and benefits of certain behaviors (Ostrom, 2005). In doing so, they make some outcomes more likely and others less likely.

\section{SHORTAGE SHARING, ROTATIONAL DELIVERY AS ADAPTATIONS TO SCARCITY}

Two universal micro-institutional features of self-governing irrigation systems - water allocation rules and water distribution rules - are especially worthy of study due to their direct and fundamental influence on water use (Ostrom, 1992). Water allocation rules pertain to how much water each farmer within an irrigation system gets, and distribution rules determine how that water reaches the farmer. Table 3 summarizes the rules which are the focus of this study: whether water allocations can be changed between individual irrigators on the same irrigation system ("shortage sharing"), and whether water is distributed to individual irrigators on the same irrigation system in a rotation or simultaneously. Important for the SLV is the fact that water rights are administered by the state at the point where water is diverted from the natural water source through a human-made diversion structure and into the human-made irrigation system. Beyond the diversion structure, the state does not interfere with how water is administered on the irrigation system except to enforce contracts.

Table 3. The four rules in use under investigation are defined.

\begin{tabular}{ll}
\hline Rules in Use & Description \\
\hline Simultaneous Delivery & $\begin{array}{l}\text { After the diversion structure is opened, water flows down the main canal and both into } \\
\text { and past individual farmer's headgates. Each individual receives water by a unit of } \\
\text { volume per unit time (e.g. cubic feet per second [cfs]). Those with rights to divert } \\
\text { water into their farm and field level distribution system do so at the same time. }\end{array}$ \\
& $\begin{array}{l}\text { After the diversion structure is opened, water flows down the main canal and into only } \\
\text { one or a defined group of individual farmer's headgates. Each individual or group } \\
\text { Rotational Delivery } \\
\text { receives water by a unit in time (e.g. days). After the de facto water right is exhausted, } \\
\text { another individual or group receives water for their turn in a predefined order. } \\
\text { No Shortage Sharing } \\
\text { There is no mechanism to change how water is allocated to users, and de facto water } \\
\text { rights are not changed in scarcity. } \\
\text { Shortage Sharing }\end{array} \quad \begin{array}{l}\text { There is a mechanism to change how water is allocated to users, and de facto water } \\
\text { rights do change in scarcity. }\end{array}$ \\
\hline
\end{tabular}

There are many criteria used to allocate water in the SLV and globally, including: underlying private water rights, shares of ownership in an irrigation company, amount of land owned, crop 
water demand, the need to water animals, user contributions to maintenance and fees, and need based on family size, among other criteria (Dinar et al., 1997). In response to drought, the amount of water allocated to irrigators that derives from the above criteria can be changed to share the burden of shortage. Sharing shortage in this study is defined as "changed water allocations" between members of a given irrigation system, which means that de facto property rights are flexible on that system. This corresponds to exchanges within System A and within System B in Figure 4. This is in contrast to the sort of shortage sharing conducted by irrigation systems studied by Smith (2016) and Cox (2010) in New Mexico where irrigation systems change allocations between each other in an inter-system arrangement (i.e. between System 1 and System 2 in Figure 4). The intra-system shortage sharing that is the focus of this study can range in complexity from bilateral agreements between irrigators (e.g. between $\mathrm{A}$ and $\mathrm{C}$ on System 1 from Figure 4), to multilateral agreements between several irrigators (e.g. between A, $\mathrm{B}$, and D on System 1 from Figure 4), and to agreements with all irrigators on the irrigation system involved (e.g. between A, B, C, and D on System 1 from Figure 4). These agreements range from ad hoc and temporary to planned in advance and long-term, and from informal handshakes to formal, written exchanges. Potential benefits of shortage sharing include allocating water to the most productive land, providing farmers with water when crops are stressed, ensuring continued cooperation of farmers, and giving farmers flexibility with their assets. Some potential drawbacks include altered hydraulic head within the canal system, modified seepage losses, modified return flows, unclear allocations among irrigators, increased monitoring costs, and negotiation costs to establish and alter the shortage sharing arrangements.

Figure 4. Diagram of two simplified irrigation systems. System 1 is upstream of System 2, as the water flows left to right. Two diversion dams of different sizes and quality allow water into the main canal or ditch. Water is then either delivered simultaneously to all users' laterals or delivered in a rotation to groups of users (e.g. lateral canals) or individuals, suffering seepage losses along the way. This water is allocated based on some de facto property right. But, if property rights are flexible, then this is deemed "shortage sharing", and users may change allocations between each other. After water has been allocated, delivered, and applied, it may run off the field onto another field or back into the ditch, seep into the ground, or enter a drain that takes the runoff into a river or another ditch. 


\section{Simplified Irrigation System Diagrams}

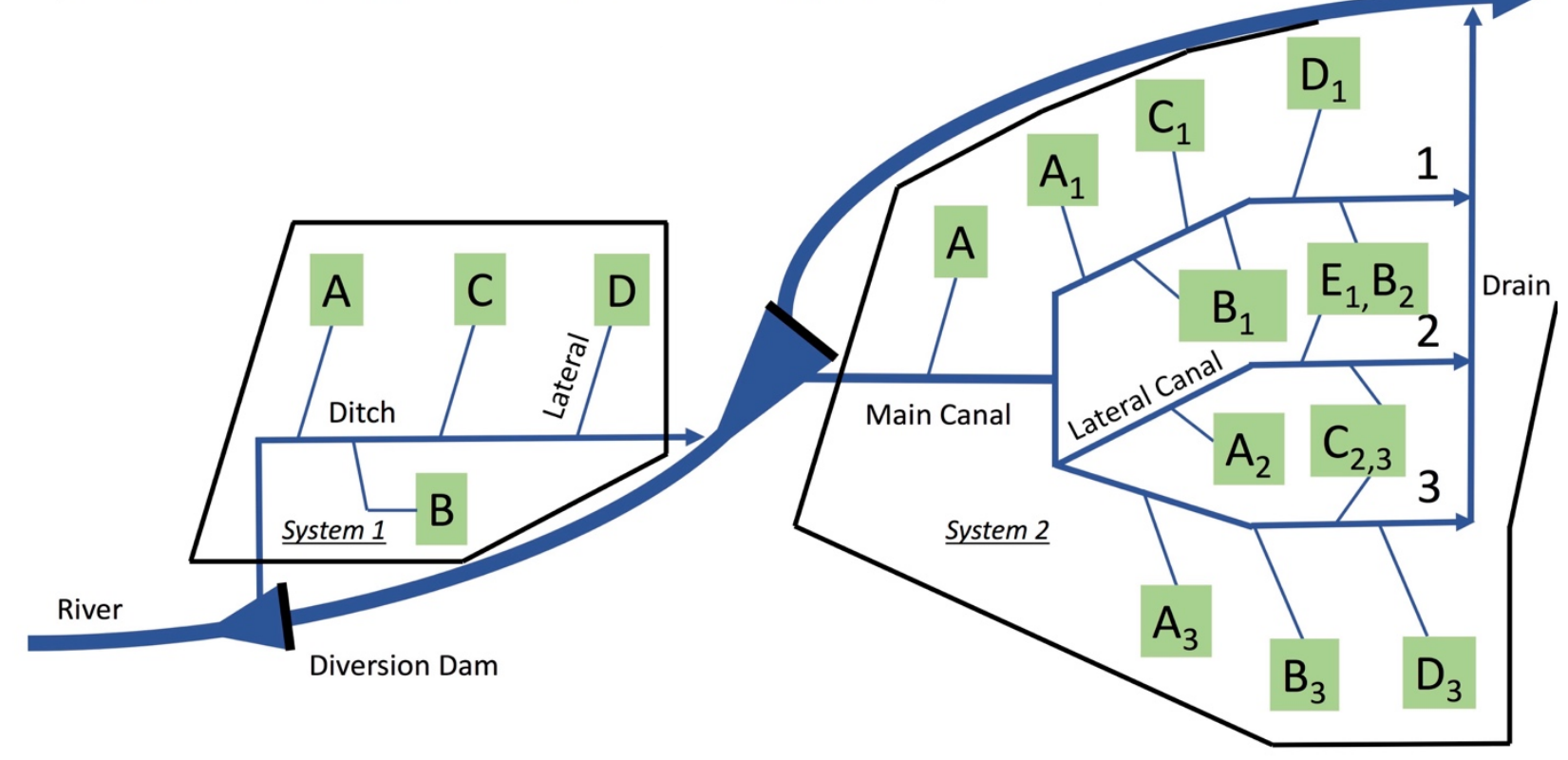

In addition to allocation rules in use, distribution rules in use are also fundamental. Irrigation systems must have some rule for delivering water once the available water is allocated. Distribution rules can also be adapted to drought conditions. Globally and in the SLV, distribution tends to occur in one of two ways (Dinar, et al., 1997). In one, simultaneous delivery, water is delivered the full length of canal system to be divided among users at the same time. In Figure 4, it would be as if A, B, C, and D on System 1 could remove their rightful rate of flow from the ditch as the water flowed past their headgates. In the other form of delivery, rotational delivery, the full flow is sent to individual farmers or groups of individuals. This would be as if water were sent, in turns of hours or days or even weeks, in some order, to the numbered laterals on System 2 from Figure 4. Some self-governing irrigation systems always rotate, regardless of hydrologic conditions, and in shortage those systems may change the rotation or not. ${ }^{1}$ In shortage, if any change in the form of delivery takes place at all, systems tend to switch from simultaneous delivery to a rotation. Potential benefits of rotation are that it may generate the necessary hydraulic head to push water the length of the ditch system, minimize seepage losses, ease monitoring of water use, affirmatively require delivery to all users, and ensure that enough water is delivered to saturate the root zone of crops. The potential drawbacks of rotation are that it can be costly to negotiate, requires more work and infrastructure investment to operate than simultaneous delivery, can deliver unequal amounts of water over equal amounts of time, and may be wasteful if individual farmers receive more water than they can use efficiently during their turn in the rotation.

${ }^{1}$ In this study, sampled irrigation systems had the opportunity to indicate whether the rotation itself changed as well as whether water allocations could be changed. Only those who answered that allocations did change were counted as sharing shortage. 
Indeed, rotation (with or without) shortage sharing has the problem of potentially having too few or too many turns during very dry years. Sending water the full length of the ditch first, as many do in order to assure the most tail-end farmer that their best chance to receive water, may prove futile and thus waste quite a bit of water. Any turn taking that does not proceed from the top to the bottom of the ditch will cause inefficient wetting of the ditch bed. Also, for some crops, it may be better to get water continuously for 30 days than just two or three times, even though pulses of flow from rotation are more efficient over a given area for a given amount of water. When pulsing with low flows and a long time between pulses, soil may lose a great deal of water in the time between turns, stressing the crops and limiting growth. Finally, if a farmer anticipates three turns but is somehow only able to get two turns in the rotation, this may be devastating. Delivering water continuously may not be optimal hydrologically, but if it is lower risk, farmers may still use it and implement other adaptations such as on-farm storage to generate pulse flows, crop changes, groundwater wells, or more efficient irrigation.

To further illustrate the connection between these rules, consider the case where delivery is normally simultaneous and shortage sharing is taking place: the user taking a cut is in fact delivering a "pulse", or increased flow rate, of water for however long the shortage sharing arrangement is in effect - be that days, weeks, or the entire season. If the arrangement takes place more than once in a season, or at a defined interval, this amounts to the rotation of the pulse. At the extreme, this pulse becomes the full flow of the ditch, which is rotated between users or groups of users. Under such a full rotation, all users but one or a few take no water for a given period, which can be seen as the result of extreme, temporary, mutual, and repeated changes in allocation (i.e. shortage sharing). And while some systems follow a full rotation at all times, and on its own this may have effects on performance that differ from simultaneous delivery, if shortage sharing is also taking place this necessarily changes the rotation itself; to allow for different final allocations of water, the delivery schedules must be altered (e.g. for irrigator $\mathrm{X}$ to receive more water than would otherwise be the case, irrigator $\mathrm{X}$ would have to start their turn in the rotation earlier). All this is to say that it is better to evaluate the effect of shortage sharing while considering its interaction with delivery.

The four institutional configurations that are possible by combining the shortage sharing and delivery rules have different implications for return flows, seepage, hydraulic head, transaction and monitoring costs, and equity, among other factors. Table 4 gives a summary of some of the implications of the four combinations of allocation and delivery rules in shortage. These implications could lead to divergent irrigation performance, measured in this study at the level of the individual irrigated field by three variables: a binary variable that measures whether a field was irrigated or not (i.e. fallowed), the percentage of a field's area that was irrigated, and the Normalized Difference Vegetation Index (NDVI) of a field (a proxy for photosynthesis and therefore intensity of crop growth).

Table 4. The projected hydrological, operational, and negotiation implications of four different institutional configurations. The degree to which these hydrological, operational, and negotiation impacts actually affect irrigation performance is unclear, and will likely depend on contextual factors such as the size of the irrigation system, its soils, its average slope, the degree of formal organization, the skill of individual irrigators, how water is normally allocated, the quality of infrastructure, and the cultural norms of irrigators, among others. 


\begin{tabular}{|c|c|c|c|}
\hline $\begin{array}{l}\text { Implications } \\
\text { for System } \\
\text { Rules in Use }\end{array}$ & Hydrology & Monitoring and Operations & Negotiations \\
\hline $\begin{array}{l}\text { Simultaneous, } \\
\text { No Shortage } \\
\text { Sharing }\end{array}$ & $\begin{array}{l}\text { 1) Divided hydraulic head, 2) higher } \\
\text { seepage loss, 3) unlikely to deliver } \\
\text { more water than can be used, 4) } \\
\text { return flows, hydraulic head, and } \\
\text { seepage unaltered by shortage } \\
\text { sharing }\end{array}$ & $\begin{array}{l}\text { 1) No affirmative delivery } \\
\text { requirement, 2) difficult to monitor all } \\
\text { users at once, } 3 \text { ) cheap to operate, 4) } \\
\text { easy to know who is owed what, 5) } \\
\text { crops cannot be salvaged }\end{array}$ & None \\
\hline $\begin{array}{l}\text { Simultaneous, } \\
\text { Shortage } \\
\text { Sharing }\end{array}$ & $\begin{array}{l}\text { 1) Divided hydraulic head, 2) higher } \\
\text { seepage loss, 3) unlikely to deliver } \\
\text { more water than can be used, 4) } \\
\text { shortage sharing may alter return } \\
\text { flows, hydraulic head, and seepage }\end{array}$ & $\begin{array}{l}\text { 1) No affirmative delivery } \\
\text { requirement, 2) difficult to monitor all } \\
\text { users at once, 3) cheap to operate, 4) } \\
\text { potentially difficult to know who is } \\
\text { owed what, 5) transfers } \\
\text { straightforward to execute, 6) crops } \\
\text { can be salvaged }\end{array}$ & $\begin{array}{l}\text { Bilateral to } \\
\text { whole ditch }\end{array}$ \\
\hline $\begin{array}{l}\text { Rotation, No } \\
\text { Shortage } \\
\text { Sharing }\end{array}$ & $\begin{array}{l}\text { 1) Concentrated hydraulic head, 2) } \\
\text { lower seepage loss, } 3 \text { ) potentially } \\
\text { delivers more water than can be } \\
\text { used, 4) return flows, hydraulic } \\
\text { head, and seepage unaltered by } \\
\text { shortage sharing }\end{array}$ & $\begin{array}{l}\text { 1) Affirmative delivery requirement, } \\
\text { 2) easy to monitor one user at a time, } \\
\text { 3) costly to operate, 4) easy to know } \\
\text { who is owed what, 5) crops cannot be } \\
\text { salvaged }\end{array}$ & $\begin{array}{l}\text { None to } \\
\text { whole ditch }\end{array}$ \\
\hline $\begin{array}{l}\text { Rotation, } \\
\text { Shortage } \\
\text { Sharing }\end{array}$ & $\begin{array}{l}\text { 1) Concentrated hydraulic head, 2) } \\
\text { lower seepage loss, } 3 \text { ) sharing } \\
\text { improves efficiency of rotation, } \\
\text { reducing waste, 4) shortage sharing } \\
\text { may alter return flows, hydraulic } \\
\text { head, and seepage }\end{array}$ & $\begin{array}{l}\text { 1) Affirmative delivery requirement, } \\
\text { 2) easy to monitor one user at a time, } \\
\text { 3) costly to operate, } 4 \text { ) potentially } \\
\text { difficult to know who is owed what, } 5 \text { ) } \\
\text { taking turns complicates transfers, } 6 \text { ) } \\
\text { crops can be salvaged }\end{array}$ & $\begin{array}{l}\text { Bilateral to } \\
\text { whole ditch }\end{array}$ \\
\hline
\end{tabular}

This study advances the literature by considering the combined effects on irrigation performance of shortage sharing and delivery method. There are numerous studies that separately investigate shortage sharing (D'Exelle et al., 2013; He et al., 2012; Torell \& Ward, 2010; Ward et al., 2013) and rotation (Abdullaev et al., 2006; Janssen et al., 2012; Turral et al., 2002). Further complicating this literature, there is not agreement as to what constitutes shortage sharing. D'Exelle et al. (2013) investigated instances where head-enders forego diversions with the intention of enabling tail-enders to irrigate (thus reducing the head-ender diversions disproportionately), finding that while this reduced efficiency, it improved equity. Ward et al. (2013) and Torell \& Ward (2010) assessed various shortage sharing arrangements, finding that an equal percentage reduction in diversions by all irrigators was flexible, easily understood, and enhanced crop production as compared to shortage arrangements that applied unequal risk burdens. He et al. (2012) also studies several mechanisms of shortage sharing under PA in Alberta, Canada where changes to water allocations were made through various inflexible rules as well as markets. They found that all modes of shortage sharing were efficiency improvements over PA, with market exchanges being the most efficient. The overall message from the literature regarding shortage sharing is that it is beneficial, especially when it is congruent with contributions to system maintenance, allocates shortage risk equitably, and is agreed upon in a transparent manner between all members of the irrigation system (Bernard et al., 2013; DaytonJohnson, 2000; Torell \& Ward, 2010; Ward et al., 2013). 
The results of rotation are similar, in that it accomplishes the goals it is implemented to achieve: rotational delivery has been found to improve equity between the head-end and tail-end (Abdullaev et al., 2006; Turral et al., 2002). Indeed, irrigators in the SLV directly stated in interviews that this was the intention of rotation. While Janssen et al. (2012) does not make this finding in an experimental setting, the rotational delivery mechanism was not accompanied by enforcement of any maximum diversion duration or amount, was not negotiated by the irrigators, and the effect of rotation was not the focus of the study. Additionally, rotation was selected by $2 / 3$ of the experimental groups of real-world irrigators in Janssen et al. (2012), possibly because irrigators understand that rotation is an effective, equitable, or at least familiar mechanism of water delivery. This does not mean that rotation is necessarily efficiency enhancing or improves crop production in the short term in aggregate, only that, under a well-functioning rotational system, the most vulnerable irrigators seem to be spared from the worse consequences of drought, in part because there is at least a de jure affirmative requirement to deliver water to every rightful irrigator for at least some duration of time - farmers in the SLV have been known to stay up all night just to be sure they get their full turn, especially if that turn lasts only hours.

While these findings are important and meaningful, the state of the literature is problematic because these two rules-in-use - allocation and distribution - are at work simultaneously and jointly influence how water moves through the physical ditch system. The effect on irrigation performance of shortage sharing likely depends on whether rotation is taking place, and the effect on irrigation performance of rotation also likely depends on whether shortage sharing is taking place. Hydrologically, shortage sharing necessarily alters how delivery takes place, and delivery necessarily alters what shortage sharing arrangements are possible (the use of turns complicates transfers); for a changed allocation to take effect, the water must be delivered in a way that changes water flow in the ditch from the pre-sharing agreement state.

Compounding the difficulty of assessing the influence of these rules-in-use is that their influence should be impacted by the degree of water scarcity and the distance a field is from the diversion structure of the irrigation system. In extreme shortage, tail-enders should be the most stressed due to seepage losses, depressed hydraulic head, and decreased return flows (Lam, 1998). Furthermore, the lack of an affirmative delivery requirement under a simultaneous delivery system can lead to "stationary bandit" behavior of head-enders (Janssen et al., 2011; Janssen et al., 2012) who use their position as the "first in line" to over-extract from the commons. However, because irrigators require ongoing collective action to maintain and operate their canal systems, it is unlikely that tail-enders would be fully deprived of water even in extreme scarcity. Depriving tail-enders of water entirely could result in damaging retaliation (gossip, sabotage, physical confrontation, etc.) and a costly decline in cooperation over time (e.g. refusal to pay fees, monitor water use, contribute labor, etc.) (Dayton-Johnson, 2000; Janssen et al., 2012; Pérez, et al., 2016). As shortage worsens, the importance of these physical heterogeneities and the differences between of rules-in-use on irrigation performance should become more pronounced (Torell \& Ward, 2010; Ward et al., 2013). The interactions between the rules-in-use and physical context are complicated and their results difficult to predict, but it is reasonable to hypothesize that these interactions are meaningful for irrigation performance.

\section{MEASURES OF IRRIGATION SYSTEM PERFORMANCE}


There are several ways in which the performance of irrigation systems may be measured (Lam, 1998; Yu et al., 2016; Ostrom, 2005; Kadirbeyoglu \& Ozertan, 2015). Because of the limits of the available data and the desire to use a replicable methodology, one of my dependent variables is that of Cox \& Ross (2011) and Smith (2016), who use multi-band satellite imagery converted to Normalized Difference Vegetation Index (NDVI) to assess crop growth in Taos, New Mexico. While it is not possible to determine what crops are being grown using NDVI, and therefore the value of the crops produced, there is ongoing use of this measurement in the literature on irrigation (Zwart \& Leclert, 2010; Li et al., 2004). If it is assumed that farmers are rationally growing the crops best suited for their soils, expected water supply, technology, and economic conditions (e.g. crop prices and market access), the intensity of crop growth as captured by NDVI should reflect overall welfare. For contexts where subsistence is of more relevance than market prices, NDVI would have even more analytical value since the overall production of crops is directly linked to survival. I assess maximum crop growth, or peak greenness, using the maximum month's NDVI as representative of the harvest in a given year.

Additionally, irrigation systems can be assessed not only for their ability to grow crops - the ultimate end of irrigation - but for their ability to apply that water to their acreage (Lam, 1998). In the SLV, the State monitors and records acreage data, and thus this study also assesses performance on this criterion. A binary irrigated/fallowed indicator is also used for each field. Some studies use the amount of water applied per unit area as a measure of irrigation performance, where more water applied indicates better performance (Yu et al., 2016). However, I lack data on the volume applied to each field. I do have the volume diverted into each ditch system and the overall acreage of that system, but for my purposes here this measure is more appropriate for representing the overall availability of water in a given year than performance.

\section{ANALYTICAL FRAMEWORK}

To analyze rules in use, I employ the Institutional Analysis and Development (IAD) framework. This follows Cox (2010) and Smith (2016), who use the IAD framework in their work in similar and geographically proximate self-governing irrigation systems in New Mexico. The IAD framework is useful for analyzing institutions in a social-ecological system because it clearly defines and separates variable concepts and can work with multiple theories (Sabatier, 2007). I also employ Common Pool Resource (CPR) theory (Ostrom, 1992; Cox, 2010; Wilson et al., 2013), which is designed to understand the management of a resource that is difficult to exclude people from using and that is depleted by its use, such as an irrigation system. CPR theory has demonstrated ability to explain outcomes in experimental, survey, and field studies of irrigation systems (Ostrom, 2005; Poteete et al., 2010). CPR theory is especially useful in this study for identifying control variables such as irrigation system acreage, irrigation technology, and cultural heritage.

\section{METHODS}

\section{Irrigation manager survey}

Prior to administering the survey, interviewees were identified using data from the Colorado Department of Natural Resources' (DNR) Decision Support Systems website. Each ditch system 
has a unique Water District ID (WDID) to which all relevant variables were associated. WDIDs were grouped based on their priority rank (above/below the median ranking in their watershed), stream location (above/below the median ranking in their watershed), and groundwater access (1/0). See Table 5 for these groupings. Additional subgroupings were made based on acreage (above/below the median ranking in the basin), and acequia status (1/0). Finally, an effort was made to balance the sample across Water Districts (WD). A random number was then assigned to every WDID, and the WDIDs within each stratified group were sorted based on this random number. The Office of the State Engineer was then contacted for assistance in contacting the WDIDs of interest, which were selected by moving down the random numbers from lowest to highest. The State Engineer contacted the Water Commissioners, who are responsible for monitoring water rights in each WD and have contact with leaders of each WDID. The Water Commissioners contacted the WDIDs of interest, and those willing to participate were scheduled for an interview.

The survey was conducted over two, two-week sampling bouts in May and June of 2013. The instrument was developed in concert with community leaders in the SLV to address questions they had as well as make theoretical abstractions more meaningful for irrigators. Surveys were administered face to face at a location of the interviewee's choosing by two to three researchers at a time, with one researcher leading the questioning and writing down answers, and the others taking notes and confirming accurate recording of responses. Each night after samples were collected the research groups came together to align their understanding of the responses and to identify where improvements to the instrument and its administration could be made. To ensure that questions were being asked the same way by different researchers, the groups of researchers were mixed each day, if not multiple times each day, and discrepancies were quickly and retroactively addressed. The average administration time was approximately 60 minutes. The surveys were conducted in English. Table 5 shows the distribution of the institutional configurations per stratified sample group.

Table 5. Summary of stratified sample groups.

\begin{tabular}{llllll}
\hline Sample Group & $\begin{array}{l}\text { Total } \\
\text { Sampled }\end{array}$ & $\begin{array}{l}\text { Rotating not } \\
\text { Sharing }\end{array}$ & $\begin{array}{l}\text { Sharing and } \\
\text { Simultaneous }\end{array}$ & $\begin{array}{l}\text { Rotating } \\
\text { and Sharing }\end{array}$ & $\begin{array}{l}\text { Simultaneou } \\
\text { s not Sharing }\end{array}$ \\
\hline Junior, Downstream, Ground & 8 & 1 & 1 & 4 & 2 \\
Junior, Downstream, No Ground & 5 & 1 & 1 & 2 & 1 \\
Junior, Upstream, Ground & 4 & 0 & 1 & 2 & 1 \\
Junior, Upstream, No Ground & 3 & 2 & 1 & 0 & 0 \\
Senior, Downstream, Ground & 8 & 0 & 2 & 3 & 3 \\
Senior, Downstream, No Ground & 17 & 1 & 3 & 9 & 4 \\
Senior, Upstream, Ground & 7 & 1 & 2 & 4 & 0 \\
Senior, Upstream, No Ground & 8 & 2 & 0 & 4 & 2 \\
\hline
\end{tabular}

See Sub-Appendix A for the text of the questions and available responses used in this analysis.

\section{Variable development and summaries}

Data were accessed using the Colorado Department of Natural Resources' (DNR) Decision Support Systems website and gathered from an irrigation manager surveys administered in 
Summer 2013. Each ditch system has a unique Water District ID (WDID) to which all relevant variables were associated. Each irrigated field (denoted as a parcel) was given a unique Master ID (MID) and had ditch level information applied to it. The geographic locations of these diversion structures, irrigation footprints, and fields were also available from the DNR's GIS database. Data were processed in R version 3.3.2 and ArcGIS 10.4 unless otherwise indicated. Some data, such as snowpack and streamflow, could not be applied directly to irrigation systems or fields. In these cases, the nearest weather station or stream gage provided the data for the irrigation system. See Table 7 for detailed summaries of the variables used.

Two independent variables of interest in the hypotheses are water availability and field distance form diversion. The volume of water diverted by the irrigation system per acre of irrigable land on that system is used to assess water availability to irrigators. It represents the most proximate measurement possible of water entering the irrigation system from the water source. It is a measure that is comparable across systems of different sizes, and is agriculturally relevant since different crops in the SLV require a certain amount of water per acre, usually between 2-4 acrefeet (Henderson, 1979a, 1979b). Field distance from diversion is measured as a straight line from the centroid of the field to the diversion structure. This approximates the distance that water must flow through the canals, ditches, and laterals to reach the field, but in all cases it is an underestimate. The measure for each field is scaled as a percentage of the largest distance a field is from the diversion of a given irrigation system. This makes the variable comparable across systems of different sizes.

Table 7. Variable descriptions and summary statistics.

\begin{tabular}{|c|c|c|}
\hline Variable Name & Measurement Summary & Descriptive Stats \\
\hline \multicolumn{3}{|l|}{ Independent Variables } \\
\hline \multirow{6}{*}{$\begin{array}{l}\text { Field Distance from } \\
\text { Diversion (DIV_DIST) }\end{array}$} & \multirow{6}{*}{$\begin{array}{l}\text { Using ArcGIS } 10.4 \text { and the DNR's GIS database, the } \\
\text { distance from each field to the diversion structure that } \\
\text { irrigates it was calculated. For each ditch system, the } \\
\text { maximum distance was determined. Each field on } \\
\text { each system was then scaled as a percentage of that } \\
\text { system's maximum distance. }\end{array}$} & $\mathrm{N}: 6711$ \\
\hline & & Min: 0.00 \\
\hline & & Med: 55.50 \\
\hline & & Mean: 54.92 \\
\hline & & Max: 100.00 \\
\hline & & SD: 22.06 \\
\hline \multirow{2}{*}{$\begin{array}{l}\text { Changes Water } \\
\text { Allocations in Shortage } \\
\text { (SHR_SRC) }\end{array}$} & \multirow{2}{*}{$\begin{array}{l}\text { Systems reporting that they make some change to how } \\
\text { water is allocated between members during shortage } \\
\text { were coded as } 1 \text {. }\end{array}$} & $\mathrm{N}: 60$ \\
\hline & & $\begin{array}{l}\text { PERCENT SHARING } \\
\text { SHORTAGE: } 65.00\end{array}$ \\
\hline \multirow{2}{*}{$\begin{array}{l}\text { Rotates Water Delivery } \\
\text { in Shortage (ROT_SRC) }\end{array}$} & \multirow{2}{*}{$\begin{array}{l}\text { Systems reporting that they rotate water delivery } \\
\text { during shortage were coded as } 1 \text {. }\end{array}$} & $\mathrm{N}: 60$ \\
\hline & & $\begin{array}{l}\text { PERCENT ROTATING IN } \\
\text { SHORTAGE: } 60.00\end{array}$ \\
\hline \multirow{6}{*}{$\begin{array}{l}\text { Acrefeet Diverted per } \\
\text { Acre } \\
\text { (AFDIV_PERDACRE) }\end{array}$} & \multirow{6}{*}{$\begin{array}{l}\text { Using the DNR's database, the total volume of water } \\
\text { diverted each year by each WDID was divided by } \\
\text { total acreage of the fields that could be irrigated. }\end{array}$} & $\mathrm{N}: 239$ \\
\hline & & Min: 0.00 \\
\hline & & Med: 1.27 \\
\hline & & Mean: 2.06 \\
\hline & & Max: 13.41 \\
\hline & & SD: 2.34 \\
\hline
\end{tabular}


Control Variables

Field Acreage

(BASEACRES)

Crop (CROP)

Water Right Rank

(WDPRIOR)

Field Distance to Stream (STRM_DIST)

Slope (SLOPE)

Field Acreage as

Percent of Total

Acreage (ACREPER)

Historical Percent of the

Irrigation System's
Using the DNR's GIS database and ArcGIS 10.4, each N: 6711

MID had its area calculated.

Min: 0.06

Med: 24.81

Mean: 54.65

Max: 759.86

SD: 59.79

Alfalfa: 9752

Grass Pasture: 10928

Potatoes: 2262

Small Grains: 2960

Other:298

N: 60

Min: 1

Med: 24.50

Mean: 52.03

Max: 311

SD: 65.83

N: 6711

Min: 0.00

Med: 2018.60

Mean: 2734.20

Max: 11488.00

SD: 2488.75

N: 60

Min: 0.08

Med: 0.46

Mean: 0.67

Max: 5.37

SD: 0.79

N: 6711

Min: 0.000407

Med: 0.150320

Mean: 0.894050

Max: 100.00

SD: 3.79

N: 60

Min: 2.63 


\author{
Maximum Acreage \\ Irrigated \\ (PERMAXACIRRAVE) \\ Historical Percent of
Average Streamflow
(PERAVAFGAGE)
}

The annual percentage of the maximum acreage irrigated by that WDID in the DNR's database averaged from 1984-2015.

The nearest stream gage upstream of a given WDID was used to calculate the percent of the historical average for that gage in the years 2011-2014. This was done using the entire range of years for which data were available for that gage.

Using the DNR's GIS database, any field irrigated using a sprinkler in a given year was coded as 1 .

Systems reporting that they have a dedicated monitoring agent, either a "ditch rider" or "mayordomo" were coded as 1.

Systems reporting a membership of 1 were coded as 1 .

Sole User (SOLEUSER)

Water Allocated Based on Land Owned or Need (LANDNEED)

Access to a Surface

Reservoir

(RES)

Acequia Status

(ACEQUIA)

Ditch System

Incorporated (INC)

Infrastructure

Problematic (INFRA)

Soil Quality Problematic (SOIL)

Southern Aspect (SOUTH)

Systems reporting that water is allocated to members according to the amount of land they own or their need were coded as 1 .

Systems reporting access to a reservoir were coded as 1.

Irrigation systems which have Spanish names or were

confirmed by locals as acequias were coded as 1 .

Systems which reported being incorporated or appeared in the Secretary of State's database of registered corporations were coded as incorporated.

On a scale of 1-5, systems reporting challenges with infrastructure on a level of 3,4 , or 5 were coded as having problematic infrastructure.

On a scale of 1-5, systems reporting challenges with soil quality on a level of 3,4 , or 5 were coded as having problematic soils.

Using the Digital Elevation Model available from USGS and the irrigation system boundaries available
Med: 66.10

Mean: 67.73

Max: 116.81

SD: 18.72

$\mathrm{N}: 240$

Min: 6.07

Med: 62.79

Mean: 61.25

Max: 100.00

SD: 25.31

N: 26844

PERCENT USING

SPRINKLERS: 31.23

$\mathrm{N}: 60$

PERCENT WITH

MONITOR: 55.00

$\mathrm{N}: 60$

PERCENT SOLE USER:

11.67

N: 60

PERCENT ALLOCATING

WATER BASED ON

LAND OWNED OR NEED:

21.67

$\mathrm{N}: 60$

PERCENT WITH

RESERVOIR: 41.67 $\mathrm{N}: 60$ from the DNR, the average aspect of each irrigation system was calculated with ArcGIS 10.3. Southwest,
PERCENT ACEQUIA:

53.33

N: 60

PERCENT

INCORPORATED: 40.00

$\mathrm{N}: 60$

PERCENT WITH

PROBLEMATIC

INFRASTRUCTURE: 40.00

$\mathrm{N}: 60$

PERCENT WITH PROBLEMATIC SOIL:

23.33

N: 60

PERCENT SOUTH

FACING: 20.00 
Acreage (DACRES)
Field Served by Multiple Ditch Systems (MULTD)

Change to Rotation (CNG2ROT)

Source Stream (WATER_SRC)
South, and Southeast were all considered as facing South to create a binary variable.

Using the DNR's GIS data, the area susceptible to irrigation by a given WDID was accessed.

Using the DNR's GIS database, any field irrigated by a groundwater well in a given year was coded as 1 .

The total number of ditch systems irrigating an MID were determined. Systems with more than one ditch system irrigating it were coded as 1 .

Systems reporting that they change their delivery mechanism from simultaneous delivery to rotational delivery were coded as 1 .

The surface stream each irrigation system diverts water from was accessed from the DNR's GIS database.
$\mathrm{N}: 60$

Min: 29.24

Med: 1122.40

Mean: 8868.20

Max: 117320.00

SD: 20840.00

$\mathrm{N}: 26844$

PERCENT IRRIGATED BY GROUNDWATER:

42.39

$\mathrm{N}: 6711$

PERCENT IRRIGATED BY MULTIPLE DITCHES: 19.74

N: 60

PERCENT CHANGING TO ROTATION: 16.0

$\mathrm{N}: 60$

RIO GRANDE: 13

CONEJOS RIVER: 10

ALAMOSA RIVER: 7

LA JARA CREEK: 6

CULEBRA: 5

SAN ANTONIO RIVER: 4

SAN FRANCISCO: 3

RITO ALTO: 2

KERBER CREEK: 2

RITO SECO: 1

COSTILLA: 1

SOUTH CUATES: 1

SAN LUIS CREEK: 1

SANGRE DE CRISTO

CREEK: 1

VALLEJOS: 1

VENTERO CREEK: 1

TORCIDO: 1

\section{Dependent Variables}

Percent Maximum

Irrigated Area

(PERIRR)

Using the DNR's data for each MID, the total largest

footprint of the field was calculated. Each year's irrigated acreage was then scaled as a percentage of this value.

\section{$\mathrm{N}: 26844$}

Min: 0.00

Med: 70.99

Mean: 50.92

Max: 100.00

SD: 45.66

$\mathrm{N}: 26844$

Monthly NDVI rasters were accessed from Google Earth Engine using LandSat images from USGS. Each month from January 2011 through December 2014 was evaluated for cloud cover, presence of frost, and
Min: 0.000

Med: 0.489 


\begin{tabular}{|c|c|c|}
\hline & overall quality. Months deemed of sufficient quality & Mean: 0.455 \\
\hline & were downloaded and loaded into ArcGIS 10.4. In & Max: 0.883 \\
\hline & GIS data representing unique MIDs, the average & SD: 0.260 \\
\hline & NDVI value for each system in each month of each & \\
\hline & year of the study period was calculated using Zonal & \\
\hline & Statistics after setting values less than 0.3 (unirrigated) & \\
\hline & to 0 . The maximum monthly value was assigned to the & \\
\hline & MID. Although not all years in the time series contain & \\
\hline & the same number of months, within each year each & \\
\hline & MID has the same number of months included in its & \\
\hline & annual average, making this average comparable & \\
\hline & across systems. & \\
\hline \multirow{3}{*}{$\begin{array}{l}\text { Irrigated/Fallowed } \\
\text { (IRRDUM) }\end{array}$} & \multirow{3}{*}{$\begin{array}{l}\text { If any portion of the MID was irrigated, this value was } \\
\text { coded as } 1 \text {. }\end{array}$} & $\mathrm{N}: 26844$ \\
\hline & & PERCENT IRRIGATED: \\
\hline & & 57.71 \\
\hline
\end{tabular}

\section{DATA ANALYSIS}

All analyses were run in R version 3.3.2 unless otherwise indicated. Cluster robust standard errors were calculated using the multiwayvcov (version 1.2.3) (Graham et al., 2016) package for R. Logistic models were estimated using the glm function in the base stats package for $\mathrm{R}$ (version 3.3.2). Tobit models were estimated using the censReg (version 0.5-26) (Henningsen, 2017) package for R. Regression tables were generated using the stargazer (version 5.2) (Hlavac, 2015) package for R. Spatial error and spatial lag models were fit using the spdep (version 0.612) (Bivand \& Piras, 2015) package for R. Effects plots were generated using the effects (version 3.1-2) (Fox, 2003) package for R.

\section{RESULTS}

Table 8 shows significant differences between head-end and tail-end fields in extreme, moderate, and minor shortage from 2011-2014.

Table 8. Head-end vs. tail-end in extreme, moderate, and minor shortage, displaying overall inequality of outcomes between the head and tail end as water availability increases. Text that is bolded, underlined, or italicized indicates a significant difference $(p<0.1)$ between head-enders ( $0 \%$ maximum distance from diversion) and tail-enders (100\% maximum distance from diversion) at the given shortage levels: extreme (833 cubic meters per hectare), moderate (4900 cubic meters per hectare), and minor (10600 cubic meters per hectare). A caret $\left({ }^{\wedge}\right)$ indicates that tail-enders outperform head-enders. Bolded years indicate a significant difference in that year when the dependent variable is binary: fallowed or irrigated. Italicized years indicate a significant difference in that year when the dependent variable is the percentage of area irrigated. Underlined years indicate a significant difference in that year when the dependent variable is NDVI. The more modified the text, the more reliable the signal. Given the number of regressions performed, there is a very high chance that some significant differences are Type I errors. Therefore, positive results for years seeing only one DV show significant differences should be taken as tenuous. Rotation shows its ability to equalize head and tail enders under almost all 
conditions, while simultaneous delivery with shortage sharing generates the most consistent inequality, especially in extreme shortage.

\begin{tabular}{|c|c|c|c|}
\hline $\begin{array}{l}\text { Institutional } \\
\text { Arrangement }\end{array}$ & $\begin{array}{l}\text { Head enders significantly } \\
\text { different from tail enders in } \\
\text { extreme shortage ( } 833 \\
\text { cubic meters per hectare)? }\end{array}$ & $\begin{array}{l}\text { Head enders significantly } \\
\text { different from tail enders in } \\
\text { moderate shortage ( } 4900 \\
\text { cubic meters per hectare)? }\end{array}$ & $\begin{array}{l}\text { Head enders significantly } \\
\text { different from tail enders in } \\
\text { minor shortage (10600 cubic } \\
\text { meters per hectare)? }\end{array}$ \\
\hline \multirow[t]{4}{*}{ Sole User } & $2011^{\wedge}$ & $2011^{\wedge}$ & $2011^{\wedge}$ \\
\hline & $2012^{\wedge}$ & $\overline{2012^{\wedge}}$ & $2012^{\wedge}$ \\
\hline & $2013^{\wedge}$ & $2013^{\wedge}$ & $2013^{\wedge}$ \\
\hline & ${\underline{2014^{\wedge}}}^{\wedge}$ & $\overline{2014^{\wedge}}$ & $\overline{2014^{\wedge}}$ \\
\hline Simultaneous & $\overline{2011}$ & 2011 & 2011 \\
\hline Delivery without & $2012^{\wedge}$ & 2012 & 2012 \\
\hline \multirow[t]{2}{*}{ Shortage Sharing } & ${\underline{2013^{\wedge}}}^{\wedge}$ & $\underline{2013}$ & 2013 \\
\hline & $\overline{2014^{\wedge}}$ & $\overline{2014}$ & $\overline{2014}$ \\
\hline Simultaneous & 2011 & $\underline{2011}$ & 2011 \\
\hline Delivery with & $\overline{2012}$ & $\overline{2012}$ & $\overline{2012}$ \\
\hline \multirow[t]{2}{*}{ Shortage Sharing } & $\underline{2013}$ & $\underline{2013}$ & 2013 \\
\hline & 2014 & $\underline{2014}$ & 2014 \\
\hline Rotational Delivery & 2011 & 2011 & 2011 \\
\hline without Shortage & 2012 & 2012 & 2012 \\
\hline \multirow[t]{2}{*}{ Sharing } & 2013 & 2013 & 2013 \\
\hline & 2014 & 2014 & 2014 \\
\hline Rotational Delivery & $\underline{2011^{\wedge}}$ & 2011 & 2011 \\
\hline with Shortage & $\overline{2012^{\wedge}}$ & 2012 & 2012 \\
\hline \multirow[t]{2}{*}{ Sharing } & 2013 & 2013 & 2013 \\
\hline & 2014 & 2014 & 2014 \\
\hline
\end{tabular}

Table 9 shows irrigation performance under extreme vs. slight shortage at the head-end, midreach, and tail-end of the irrigation system from 2011-2014.

Table 9. Irrigation performance under extreme vs. slight shortage at the head-end, mid-reach, and tail-end of the irrigation system, displaying overall inequality of marginal productivity between the head and tail end as water availability increases. Text that is bolded, underlined, or italicized indicates a significant difference $(p<0.1)$ between extreme $(0$ cubic meters per hectare) and slight shortage (12,335 cubic meters per hectare) at the given distance from the diversion structure. A caret $\left({ }^{\wedge}\right)$ indicates that more water produces significantly worse outcomes. Bold years indicate a significant difference in that year when the dependent variable is binary: fallowed or irrigated. Italicized years indicate a significant difference in that year when the dependent variable is the percentage of the total area irrigated. Underlined years indicate a significant difference in that year when the dependent variable is NDVI. The more modified the text, the more reliable the signal. Given the number of regressions performed, there is a very high chance that some significant differences are Type I errors. Therefore, positive results for years seeing only one DV show significant differences should be taken as tenuous. Rotation with shortage sharing shows its ability to improve outcomes equally up and down the ditch as more water becomes available, something simultaneous delivery fails to do for the tail-end. Shortage sharing with simultaneous delivery is the weakest arrangement when it comes to allocating increased water supplies to produce increased crop growth.

\begin{tabular}{llll}
\hline Institutional & $\begin{array}{l}\text { Extreme shortage } \\
\text { significantly different from }\end{array}$ & $\begin{array}{l}\text { Extreme shortage } \\
\text { significantly different from }\end{array}$ & $\begin{array}{l}\text { Extreme shortage } \\
\text { significantly different from }\end{array}$ \\
\hline
\end{tabular}




\begin{tabular}{|c|c|c|c|}
\hline & $\begin{array}{l}\text { slight shortage for head end } \\
(5 \%) ?\end{array}$ & $\begin{array}{l}\text { slight shortage for mid ditch } \\
(50 \%) ?\end{array}$ & $\begin{array}{l}\text { slight shortage for tail end } \\
(95 \%) ?\end{array}$ \\
\hline \multirow[t]{4}{*}{ Sole User } & 2011 & 2011 & 2011 \\
\hline & 2012 & 2012 & 2012 \\
\hline & $\overline{2013}$ & 2013 & 2013 \\
\hline & 2014 & 2014 & 2014 \\
\hline Simultaneous & $\underline{2011}$ & 2011 & 2011 \\
\hline Delivery without & $\underline{2012}$ & 2012 & 2012 \\
\hline \multirow[t]{2}{*}{ Shortage Sharing } & $\overline{2013}$ & $\overline{2013}^{\wedge}$ & ${\underline{2013^{\wedge}}}^{\wedge}$ \\
\hline & $\underline{2014}$ & $\underline{2014}$ & 2014 \\
\hline Simultaneous & $\overline{2011}$ & 2011 & 2011 \\
\hline Delivery with & 2012 & 2012 & 2012 \\
\hline \multirow[t]{2}{*}{ Shortage Sharing } & 2013 & 2013 & $\overline{2013}$ \\
\hline & 2014 & 2014 & 2014 \\
\hline Rotational Delivery & $\underline{2011^{\wedge}}$ & $\underline{2011^{\wedge}}$ & $\underline{2011^{\wedge}}$ \\
\hline without Shortage & 2012 & $2012^{\wedge}$ & $2012^{\wedge}$ \\
\hline \multirow[t]{2}{*}{ Sharing } & $\underline{2013^{\wedge}}$ & $\underline{2013^{\wedge}}$ & $2013^{\wedge}$ \\
\hline & $2014^{\wedge}$ & $\underline{2014^{\wedge}}$ & $\underline{2014^{\wedge}}$ \\
\hline \multirow{4}{*}{$\begin{array}{l}\text { Rotational Delivery } \\
\text { with } \\
\text { Shortage Sharing }\end{array}$} & $\underline{2011}$ & 2011 & 2011 \\
\hline & $\overline{2012}$ & $\overline{2012}$ & $\overline{2012}$ \\
\hline & $\underline{2013}$ & 2013 & $\underline{2013}$ \\
\hline & $\overline{2014}$ & 2014 & 2014 \\
\hline
\end{tabular}

Table 10 shows the Variance Inflation Factor (VIF) of each variable in the regression model without any interactions for NDVI in the years 2011-2014. VIF evaluates whether multicollinearity is a threat to the model. VIFs less than 5 warrant little to no concern, between 5 and 10 warrant some concern, and greater than 10 are concerning. In cases where categorical variables have more than two levels, it is very common for these variables to be correlated with each other due to being mutually exclusive. However, these VIFs are not a concern for estimation. Overall, these VIF values indicate there is not a problem with multicollinearity despite some control variables having greater uncertainty in their parameter estimates. Thankfully, they are not the independent variables of interest.

Table 10. Variance Inflation Factors for all right hand side variables in the regressions predicting NDVI for 2011-2014 without interactions.

\begin{tabular}{lllll}
\hline Variable & VIF 2014 & VIF 2013 & VIF 2012 & VIF 2011 \\
\hline Sprinkler Use & 3.8278152 & 3.7518914 & 3.7578638 & 3.7866480 \\
Crop: Grass Pasture & 1.6414125 & 1.6765613 & 1.7166795 & 1.7684032 \\
Crop: Other & 1.1343633 & 1.0960616 & 1.0998582 & 1.0914590 \\
Crop: Potatoes & 1.5198280 & 1.4360847 & 1.5152300 & 1.4679550 \\
Crop: Small Grains & 1.3610961 & 1.3373053 & 1.3435003 & 1.4167290 \\
Groundwater Well & 2.2351588 & 2.1668657 & 2.1553746 & 2.1724131 \\
Percent Average at Upstream Gage & 16.6775318 & 10.9307354 & 13.6427771 & 21.0036279 \\
Water Source: Alamosa River & 5.9920485 & 4.1427074 & 6.3086494 & 4.8427485 \\
Water Source: Conejos River & 19.9043486 & 13.9524251 & 11.2981428 & 10.2829619 \\
Water Source: Costilla & 1.4698890 & 1.4240287 & 1.5636878 & 1.5492016 \\
Water Source: Culebra & 6.4711663 & 7.4042719 & 6.0503332 & 4.6649999 \\
Water Source: Kerber Creek & 1.1721786 & 1.1502459 & 1.4740857 & 1.2027849 \\
Water Source: La Jara Creek & 3.2518961 & 2.2520512 & 2.7539889 & 3.3051075 \\
Water Source: Rito Alto Creek & 1.5839317 & 1.8635004 & 1.5817275 & 1.8352106 \\
Water Source: Rito Seco & 1.4054535 & 1.3906791 & 1.3646354 & 1.3737055
\end{tabular}




\begin{tabular}{lllll} 
Water Source: San Antonio River & 7.0245113 & 2.2926309 & 3.5966525 & 3.4865761 \\
Water Source: San Francisco & 1.8417101 & 1.6786916 & 1.7830160 & 1.7335238 \\
Water Source: San Luis Creek & 2.1456019 & 1.9003231 & 3.9746922 & 2.2001832 \\
Water Source: Sangre de Cristo Creek & NA & 9.7486174 & 10.8513377 & 23.5955826 \\
Water Source: Torcido & 1.7273416 & 1.6307968 & 1.6208106 & 1.6343547 \\
Water Source: Vallejos & 3.9177703 & 3.9554984 & 3.7000088 & 3.2501843 \\
Water Source: Ventero Creek & 1.3252967 & 1.4121848 & 1.2727628 & 1.2945855 \\
Reservoir Access & 4.7193526 & 4.4707373 & 5.2348221 & 4.3144140 \\
Soil Problematic & 7.2721918 & 7.6214630 & 7.4329210 & 7.4146055 \\
Irrigated by Multiple Ditches & 1.8037757 & 1.7840165 & 1.8107214 & 1.8010993 \\
Incorporated & 4.0522881 & 3.7161624 & 4.2561767 & 4.1306042 \\
Infrastructure Problematic & 5.2949085 & 4.6644303 & 6.5031044 & 5.4208852 \\
Water Allocated on Land or Need & 6.4224089 & 9.3429774 & 7.1679891 & 7.2237939 \\
Acequia Status & 6.5678125 & 6.6484557 & 6.5970076 & 6.8194917 \\
South Facing Aspect & 4.5435582 & 4.1737216 & 4.4216460 & 4.6552427 \\
Slope & 4.0504562 & 5.0812529 & 5.0342402 & 5.0460654 \\
Field Distance from Stream & 1.7735953 & 1.8099913 & 1.8111702 & 1.8032552 \\
Field Acreage & 2.3151555 & 2.3471280 & 2.3251827 & 2.3385427 \\
Field/Ditch Area Ratio & 2.7596787 & 2.6098236 & 2.5714253 & 2.5955805 \\
Ditch Area & 8.6554965 & 8.9267421 & 8.5877171 & 8.5814276 \\
Water Right Priority Rank & 2.9711476 & 3.2147236 & 3.2944396 & 3.1580603 \\
Percent Maximum Area Irrigated on Average & 4.6054443 & 5.3652499 & 6.0826844 & 4.8909644 \\
Monitoring Agent & 3.4964531 & 3.2299231 & 3.6496256 & 3.5894548 \\
Change to Rotation in Shortage & 9.4516778 & 10.7399566 & 10.4235103 & 10.4403282 \\
Shortage Sharing & 4.8418098 & 6.0573840 & 5.0105858 & 5.0553329 \\
Rotate in Scarcity & 4.9944195 & 5.1401251 & 5.4416675 & 5.8931444 \\
Water Availability & 4.2724653 & 5.0747121 & 6.5360112 & 4.5920558 \\
Field Distance from Diversion & 1.2018021 & 1.2030769 & 1.1948040 & 1.2022178 \\
\hline
\end{tabular}

\section{Comments on statistical significance}

There are some shortcomings to the sample. The sample of irrigation systems is not balanced across the institutional configurations, and this lack of balance is even more pronounced at the field-level. This helps explain why some of the confidence bands are as large as they are, especially for rotational delivery without sharing. Additionally, there are relatively few fields at the extreme head and tail-end of systems, which helps explain why the confidence bands become so large at the extreme ends of the x-axis. That said, although statistical significance is a crucial guide for assessing the precision of results, the consistency of the trends across years and different dependent variables are encouraging. Additionally, statistical significance does not equate to agricultural significance. When predicted NDVI lies, with $90 \%$ or $95 \%$ confidence, between 0.19 to 0.4 under one institutional configuration and 0.39 to 0.6 in another, these are meaningful differences to farmers even if they are not statistically different estimates.

\section{DEALING WITH ENDOGENEITY}

Over time, irrigation systems adopt rules based on the feedback irrigators receive from past performance (Ostrom, 2014). It could therefore be argued that the effects I find for different rules in use actually reflect past irrigation performance and/or the factors shaping past irrigation performance, not the current rules. I address this concern in three ways. First, I explain the problem and address the endogeneity argument conceptually. Second, I describe the steps taken 
in data analysis to address whatever endogeneity may be present. Third, I discuss the contradictory endogeneity stories that could be present in the data.

Additionally, even if an irrigation system may select a set of rules based on the performance it has had in the recent past and generally has had for other reasons, it is still interesting and useful to know what the deeper features of that performance are, specifically the relationship between head and tail-enders and marginal productivity. If the causal link goes the other way, the fact that there is a significant relationship is interesting and deserves the chance to be explained causally. Put another way, if these configurations are considered different solution spaces or basins of attraction that require mutually reinforcing institutions, physical contexts, and social processes, then knowing the significant features of those solution spaces or basins of attraction will be useful to efforts to adapt to climate change.

\section{The conceptual argument against endogeneity}

Lam (1998) covers the problem of endogeneity well on page 51, and I quote him at length. He begins by presenting the argument that "FIMS [Farmer Managed Irrigation Systems] that did not attain high levels of performance would have either died out, or had to learn from more successful FIMS how to craft more effective rules to improve their performance." That is, the institutional arrangements of self-governing irrigation systems he observes in Nepal are products of Darwinian selection based on irrigation performance, and therefore the rules in use are endogenous. In response, he states:

While it would be reasonable to believe that a selection process is at work to a certain extent, the magnitude of the effect of such a process should not be overstated. As argued by political economics (North, 1990; E. Ostrom, 1990), while surviving institution arrangements are not necessarily effective, ineffective institutional arrangements could persist for a long period of time. On the one hand, an institutional arrangement is likely to give rise to vested interests with incentives to maintain the status quo arrangement (Knight, 1992). ... On the other hand, one should not assume that farmers in less effective FIMS would necessarily be able to learn from farmers in more effective systems in crafting effective rules. Institutional development is path-dependent (North, 1990; E. Ostrom, 1990; Blomquist, 1992). The kinds of change that are conceivable and practically possible are frequently determined by the status quo condition.

So, while feedbacks do occur, they do so slowly and may not actually generate aggregate net improvements; changes can occur which increase inequality and which promote particular interests over others. ${ }^{2}$ And while certain factors and outcomes may make some rules in use more likely, they do not prescribe them by necessity nor negate the effects of the rules. ${ }^{3}$ Although these farmers are competing in a market context, provided that they can maintain economic

\footnotetext{
${ }^{2}$ See Cody et al. (2015) for an in-depth discussion of the path-dependent nature of institutional change using the groundwater commons in the SLV as an example.

3 While on a very different time scale, the fact that the shape of a fish's fin has been selected for swimming efficiency does not imply that different efficiencies measured across variations in fin shape are merely measurements of previous swimming efficiencies and ecological contexts.
} 
viability, differential outcomes may not produce the degree of selection pressure scholars might think.

A crucial factor mitigating concerns about endogeneity in the SLV that the irrigation systems are very old, all being founded over 100 years ago. Their bylaws and norms have been established for many decades and it is costly to make changes, especially in a single season. Most farmers interviewed were able to describe their shortage sharing and delivery rules in great detail and without reflection, indicating that they had grown quite accustomed to the operations of the system over a long period of time. Many also had complaints about the rules, indicating that they viewed the rules as important for determining irrigation performance and not perfectly adapted.

\section{Accounting for endogeneity in the analysis}

While there is undoubtedly some institutional adaptation over time, provided that I account for the major factors that might shape rule selection in my regressions, I can be confident in my results. Table 6 shows the distribution of some key variables that could shape performance and rule adoption. I pay special attention to performance, because this is the greatest threat to my regression results. To account for any endogeneity in my final regressions, I include the historical average percentage of the irrigation system's acreage irrigated from 1984-2015 as well as water right priority. These variables could influence the adoption of shortage mitigating rules, so the inclusion of these variables reduces the chance that the variation introduced by this feedback is being absorbed by the rules in use. As another hedge against endogeneity, I use multiple years in my analysis to assess the effects of the institutional configurations in 2013. Interviews with irrigators make me confident that I can assume that over the short term (1-5 years) these institutional configurations are essentially stable, so that 2011, 2012, and 2014 have the same shortage sharing and delivery rules as those assessed in 2013. Importantly, there is no conceptual way that 2013 or 2014 performance could influence the rules used in 2013.

\section{Contradictory endogeneity stories in the data}

Finally, if the effects I find for the variables of interest are in the opposite direction from what would be expected if the signal were endogenous, I can be further assured that endogeneity is not influencing my results. In my case, I expect shortage sharing and rotation to improve outcomes, whereas if the signal were endogenous, the observed effects of these rules would be negative. That is, worse performance should be associated with the adoption of these rules if these rules are adopted to mitigate poor performance. However, an alternative endogeneity story posits that stronger performance leads to the adoption of these rules, because higher economic productivity facilitates collective action. Overall, the results do not support either endogeneity story. The results show that systems with simultaneous delivery and no shortage sharing are strong performers. This implies that the only endogeneity story that could be operating is that poor performance leads to the adoption of institutions for shortage mitigation: having strong performance, these systems had no need to adopt rules that adapt operations to shortage. However, systems that have adopted both shortage sharing and rotation also have strong performance; in this case, the only endogeneity story that could be operating is that strong performance creates the capital necessary to organize collective action. These two examples from the data falsify each other. So, while it is possible that both endogeneity stories are playing 
out with different strengths on different irrigation systems, the parsimonious interpretation is that endogeneity is not behind the results. 
Table 6. Key variables that may influence the selection of particular institutional configurations. Descriptive statistics given here are at the level of the irrigation system, not fields. There is an added category, Sole User, which indicates an irrigation system owned by

\begin{tabular}{|c|c|c|c|c|c|c|c|}
\hline Rules in Use & Size & $\begin{array}{l}\text { Average } \\
\text { Performance } \\
(1984-2015)\end{array}$ & Water Reliability & $\begin{array}{l}\text { Irrigation } \\
\text { Technology } \\
(2011-2014)\end{array}$ & $\begin{array}{l}\text { Formality, } \\
\text { Monitoring, } \\
\text { Allocation }\end{array}$ & $\begin{array}{l}\text { Crops } \\
(2011- \\
2014)\end{array}$ & Social Context \\
\hline $\begin{array}{l}\text { Sole User } \\
(7,11.7 \%)\end{array}$ & $\begin{array}{l}\text { Average } \\
\text { Acreage: } 619 \\
\text { Average Field } \\
\text { Distance: } \\
1.657 \mathrm{~km}\end{array}$ & $\begin{array}{l}\text { Percent } \\
\text { Maximum } \\
\text { Diversion: } \\
44.5 \% \\
\text { Percent } \\
\text { Irrigated: } 57.9 \%\end{array}$ & $\begin{array}{l}\text { Water Right } \\
\text { Percentile: } 25.8 \\
\text { Catchment Area: } \\
224,090 \\
\text { Reservoir Access: } \\
42.9 \%\end{array}$ & $\begin{array}{l}\text { Acreage w/ } \\
\text { Wells: } \\
10.1 \% \\
\text { Acreage w/ } \\
\text { Sprinklers: } \\
4.3 \%\end{array}$ & $\begin{array}{l}\text { Incorporated: } \\
14.3 \% \\
\text { Monitoring: NA } \\
\text { Allocate on Water } \\
\text { Rights or Shares: } \\
\text { NA }\end{array}$ & $\begin{array}{l}\text { Grass } \\
\text { Pasture: } \\
78.9 \% \\
\text { Alfalfa: } \\
10.3\end{array}$ & $\begin{array}{l}\text { Acequia: } 28.6 \% \\
\text { Average Users: } \\
1.0 \\
\text { Acres per User: } \\
619\end{array}$ \\
\hline $\begin{array}{l}\text { Simultaneous, } \\
\text { No Shortage } \\
\text { Sharing } \\
(6,10 \%)\end{array}$ & $\begin{array}{l}\text { Average } \\
\text { Acreage: } 8,172 \\
\text { Average Field } \\
\text { Distance: } \\
8.888 \mathrm{~km}\end{array}$ & $\begin{array}{l}\text { Percent } \\
\text { Maximum } \\
\text { Diversion: } \\
55.3 \% \\
\text { Percent } \\
\text { Irrigated: } 55.8 \%\end{array}$ & $\begin{array}{l}\text { Water Right } \\
\text { Percentile: } 18.1 \\
\text { Catchment Area: } \\
441,630 \\
\text { Reservoir Access: } \\
50.0 \%\end{array}$ & $\begin{array}{l}\text { Acreage w/ } \\
\text { Wells: } \\
42.7 \% \\
\text { Acreage w/ } \\
\text { Sprinklers: } \\
43.0 \%\end{array}$ & $\begin{array}{l}\text { Incorporated: } \\
83.3 \% \\
\text { Monitoring: } 100 \% \\
\text { Allocate on Water } \\
\text { Rights or Shares: } \\
100 \%\end{array}$ & $\begin{array}{l}\text { Grass } \\
\text { Pasture: } \\
68.7 \% \\
\text { Alfalfa: } \\
19.5 \%\end{array}$ & $\begin{array}{l}\text { Acequia: } 50 \% \\
\text { Average Users: } \\
45.0 \\
\text { Acres per User: } \\
279\end{array}$ \\
\hline $\begin{array}{l}\text { Simultaneous, } \\
\text { Shortage } \\
\text { Sharing } \\
(11,18.3 \%)\end{array}$ & $\begin{array}{l}\text { Average } \\
\text { Acreage: } \\
21,950 \\
\text { Average Field } \\
\text { Distance: } \\
8.944 \mathrm{~km}\end{array}$ & $\begin{array}{l}\text { Percent } \\
\text { Maximum } \\
\text { Diversion: } \\
52.1 \% \\
\text { Percent } \\
\text { Irrigated: } 66.7 \%\end{array}$ & $\begin{array}{l}\text { Water Right } \\
\text { Percentile: } 21.3 \\
\text { Catchment Area: } \\
445,700 \\
\text { Reservoir Access: } \\
72.7 \%\end{array}$ & $\begin{array}{l}\text { Acreage w/ } \\
\text { Wells: } \\
51.6 \% \\
\text { Acreage w/ } \\
\text { Sprinklers: } \\
56.4 \%\end{array}$ & $\begin{array}{l}\text { Incorporated: } \\
45.5 \% \\
\text { Monitoring: } 54.6 \% \\
\text { Allocate on Water } \\
\text { Rights or Shares: } \\
90.9 \%\end{array}$ & $\begin{array}{l}\text { Grass } \\
\text { Pasture: } \\
43.2 \% \\
\text { Alfalfa: } \\
38.0 \%\end{array}$ & $\begin{array}{l}\text { Acequia: } 36.4 \% \\
\text { Average Users: } \\
44.4 \\
\text { Acres per User: } \\
512\end{array}$ \\
\hline $\begin{array}{l}\text { Rotation, No } \\
\text { Shortage } \\
\text { Sharing } \\
(8,13.3 \%)\end{array}$ & $\begin{array}{l}\text { Average } \\
\text { Acreage: } 951 \\
\text { Average Field } \\
\text { Distance: } \\
3.686 \mathrm{~km}\end{array}$ & $\begin{array}{l}\text { Percent } \\
\text { Maximum } \\
\text { Diversion: } \\
46.2 \% \\
\text { Percent } \\
\text { Irrigated: } 53.1 \%\end{array}$ & $\begin{array}{l}\text { Water Right } \\
\text { Percentile: } 35.9 \\
\text { Catchment Area: } \\
82,381 \\
\text { Reservoir } \\
\text { Access: } 12.5 \%\end{array}$ & $\begin{array}{l}\text { Acreage w/ } \\
\text { Wells: } \\
15.3 \% \\
\text { Acreage w/ } \\
\text { Sprinklers: } \\
18.9 \%\end{array}$ & $\begin{array}{l}\text { Incorporated: } \\
25.0 \% \\
\text { Monitoring: } 25.0 \% \\
\text { Allocate on Water } \\
\text { Rights or Shares: } \\
50.0 \%\end{array}$ & $\begin{array}{l}\text { Grass } \\
\text { Pasture: } \\
52.7 \% \\
\text { Alfalfa: } \\
37.5 \%\end{array}$ & $\begin{array}{l}\text { Acequia: } 75 \% \\
\text { Average Users: } \\
10.3 \\
\text { Acres per User: } \\
162\end{array}$ \\
\hline $\begin{array}{l}\text { Rotation, } \\
\text { Shortage } \\
\text { Sharing } \\
(28,46.7 \%)\end{array}$ & $\begin{array}{l}\text { Average } \\
\text { Acreage: } 8,202 \\
\text { Average Field } \\
\text { Distance: } \\
5.443 \mathrm{~km}\end{array}$ & $\begin{array}{l}\text { Percent } \\
\text { Maximum } \\
\text { Diversion: } \\
54.2 \% \\
\text { Percent } \\
\text { Irrigated: } 63.5 \%\end{array}$ & $\begin{array}{l}\text { Water Right } \\
\text { Percentile: } 20.0 \\
\text { Catchment Area: } \\
313,260 \\
\text { Reservoir } \\
\text { Access: } 35.7 \%\end{array}$ & $\begin{array}{l}\text { Acreage w/ } \\
\text { Wells: } \\
30.6 \% \\
\text { Acreage w/ } \\
\text { Sprinklers: } \\
34.8 \%\end{array}$ & $\begin{array}{l}\text { Incorporated: } \\
39.3 \% \\
\text { Monitoring: } 67.9 \% \\
\text { Allocate on Water } \\
\text { Rights or Shares: } \\
60.1 \%\end{array}$ & $\begin{array}{l}\text { Grass } \\
\text { Pasture: } \\
36.5 \% \\
\text { Alfalfa: } \\
43.0 \%\end{array}$ & $\begin{array}{l}\text { Acequia: } 60.7 \% \\
\text { Average Users: } \\
22.2 \\
\text { Acres per User: } \\
208\end{array}$ \\
\hline
\end{tabular}




$\begin{array}{llllllll}\text { Overall } & \text { Average } & \text { Percent } & \text { Water Right } & \text { Acreage w/ } & \text { Incorporated: } & \text { Grass } & \text { Acequia: } 53.3 \% \\ (60,100 \%) & \text { Acreage: } 8,868 & \text { Maximum } & \text { Percentile: } 22.8 & \text { Wells: } & 40.0 \% & \text { Pasture: } & \text { Average Users: } \\ & \text { Average Field } & \text { Diversion: } & \text { Catchment Area: } & 31.2 \% & \text { Monitoring: } 55.0 \% & 46.9 \% & 24.6 \\ & \text { Distance: } & 51.7 \% & 309,190 & \text { Acreage w/ } & \text { Allocate on Water } & \text { Alfalfa: } & \text { Acres per User: } \\ & 5.754 \mathrm{~km} & \text { Percent } & \text { Reservoir Access: } & \text { Sprinklers: } & \text { Rights or Shares: } & 36.2 \% & 302 \\ & & \text { Irrigated: } 61.2 \% & 41.7 \% & 33.9 \% & 61.7 \% & & \\ & & & & & \end{array}$




\section{LITERATURE CITED}

1. Abdullaev, I., U1 Hassan, M., Manthrithilake, H., \& Yakubov, M. 2006. The Reliability Improvement in Irrigation Services: Application of Rotational Water Distribution to Tertiary Canals in Central Asia. IWMI Research Report 100. Colombo, Sri Lanka.

2. Adler, R.W. 2010. Climate Change and the Hegemony of State Water Law. Stanford Environmental Law Journal, Vol. 29, No. 1.

3. Bernard, M., Dreber, A., Strimling, P., \& Eriksson, K. 2013. The subgroup problem: When can binding voting on extractions from a common pool resource overcome the tragedy of the commons? Journal of Economic Behavior and Organization, 91, 122-130

4. Bivand, R. \& Piras, G. 2015. Comparing Implementations of Estimation Methods for Spatial Econometrics. Journal of Statistical Software, 63(18), 1-36.

5. Blomquist, W. 1992. Dividing the Waters: Governing Groundwater in Southern California. San Francisco: ICS Press.

6. Cody, K., Smith, S., Cox, M., Andersson, K. 2015. Emergence of Collective Action in a Groundwater Commons: Irrigators in the San Luis Valley of Colorado. Society and Natural Resources, 28(4): 405-422.

7. Cox, M. 2010. Exploring the dynamics of social-ecological systems: the case of the Taos valley acequias (Doctoral dissertation). Retrieved from ProQuest Dissertations and Theses database. (UMI No. 3397459)

8. Cox, M. 2014. Modern disturbances to a long-lasting community-based resource management system: The Taos Valley Acequias. Global Environmental Change 24: 213 222.

9. Cox, M., and J. Ross. 2011. Robustness and vulnerability of community irrigation systems: The case of the Taos Valley Acequias. J. Environ. Econ. Manage. 61(3): 254266.

10. D’Exelle, B., Lecoutere, E., \& Van Campenhout, B. 2012. Equity-Efficiency Trade-Offs in Irrigation Water Sharing: Evidence from a Field Lab in Rural Tanzania. World Development, 40(12), 2537-2551.

11. Dayton-Johnson, J. 2000. Choosing rules to govern the commons: a model with evidence from Mexico. Journal of Economic Behavior \& Organization, 42(1), 19-41

12. Department of Natural Resources (DNR). N.D. Colorado's Decision Support Systems. Accessed Feb 16, 2017: http://cdss.state.co.us/basins/Pages/RioGrande.aspx

13. Dinar, A., Rosegrant, M.W., Meinzen-Dick, R. 1997. Water allocation mechanisms: principles and examples. Policy, Research working paper; no. WPS 1779. Washington, DC: World Bank.

14. Fernald, A., Tidwell, V., Rivera, J., Rodríguez, S., Guldan, S., Steele, C., Ochoa, C., Hurd, B., Ortiz, M., Boykin, K., \& Cibils, A. 2012. Modeling Sustainability of Water, Environment, Livelihood, and Culture in Traditional Irrigation Communities and Their Linked Watersheds. Sustainability, 4(12): 2998-3022.

15. Fox, J. 2003. Effect Displays in R for Generalized Linear Models. Journal of Statistical Software, 8(15): 1-27.

16. Graham, N., Arai, M., Hagströmer, B. 2016. multiwayvcov: Multi-Way Standard Error Clustering. R package version 1.2.3. https://CRAN.R-project.org/package=multiwayvcov 
17. He, L., Horbulyk, T. M., Ali, M. K., Le Roy, D. G., \& Klein, K. K. 2012. Proportional water sharing vs. seniority-based allocation in the Bow River basin of Southern Alberta. Agricultural Water Management, 104, 21-31.

18. Henderson, D. 1979a. Engineering Report Water Districts Nos. 21 \& 22 Conejos and Alamosa Counties Colorado. The Federal Land Bank of Wichita.

19. Henderson, D. 1979b. Revisions Water District 20 Rio Grande River and Tributaries San Luis Valley, Colorado. The Federal Land Bank of Wichita.

20. Henningsen, A. 2017. censReg: Censored Regression (Tobit) Models. R package version 0.5-26. https://CRAN.R-project.org/package=censReg

21. Hlavac, Marek. 2015. stargazer: Well-Formatted Regression and Summary Statistics Tables. R package version 5.2. http://CRAN.R-project.org/package=stargazer

22. Howe, C.W., Alexander, P.K, \& Moses, R.J. 1982. The Performance of Appropriative Water Rights Systems in the Western United States During Drought. Natural Resource Journal, 22(2): 379-389.

23. Janssen, M. A., Anderies, J. M., \& Cardenas, J. C. 2011. Head-enders as stationary bandits in asymmetric commons: Comparing irrigation experiments in the laboratory and the field. Ecological Economics, 70(9): 1590-1598.

24. Janssen, M. A., Bousquet, F., Cardenas, J. C., Castillo, D., \& Worrapimphong, K. 2012. Field experiments on irrigation dilemmas. Agricultural Systems, 109, 65-75.

25. Janssen, M. A., \& Anderies, J. M. 2013. A multi-method approach to study robustness of social-ecological systems: the case of small-scale irrigation systems. Journal of Institutional Economics, 9(04): 427-447.

26. Kadirbeyoglu, Z., \& Ozertan, G. 2015. Power in the Governance of Common-Pool Resources: A comparative analysis of irrigation management decentralization in Turkey. Environmental Policy and Governance, 25: 157-171.

27. Kenney, D. 2005. Prior Appropriation and Water Rights Reform in the Western United States. In Bruns, B., Ringler, C., Meinzen-Dick, R (Eds.), Water Rights Reform: Lessons for Institutional Design: pp. 167-182. Washington, D.C.: International Food Policy Research Institute.

28. Knight, J. 1992. Institutions and Social Conflict. Cambridge: Cambridge University Press.

29. Lam, W.F. 1998. Governing Irrigation Systems in Nepal: Institutions, Infrastructure, and Collective Action. Oakland, CA: Institute for Contemporary Studies.

30. Li, J., Lewis, J., Rowland, J., Tappan, G., Tieszen, L. 2004. Evaluation of land performance in Senegal using multi-temporal NDVI and rainfall series. Journal of Arid Environments, 59: 463-480.

31. Lukas, J., Barsugli, J., Doesken, J., Rangwala, I., Wolter, K. 2014. Climate Change in Colorado: A Synthesis to Support Water Resources Management and Adaptation. A report for the Colorado Water Conservation Board by Western Water Assessment. Boulder, $\mathrm{CO}$.

32. Mix, K., Lopes, V. L., \& Rast, W. 2012. Growing season expansion and related changes in monthly temperature and growing degree days in the Inter-Montane Desert of the San Luis Valley, Colorado. Climatic Change, 114(3-4): 723-744.

33. Mix, K., Lopes, V. L., \& Rast, W. 2012. Growing season expansion and related changes in monthly temperature and growing degree days in the Inter-Montane Desert of the San Luis Valley, Colorado. Climatic Change, 114(3-4): 723-744. 
34. Mix, K., V. Lopes, and W. Rast. 2011. Annual and growing season temperature changes in the San Luis Valley, Colorado. Water Air Soil Pollut. 220(1): 189-203.

35. Mix, K., Rast, W., \& Lopes, V. L. 2009. Increases in Growing Degree Days in the Alpine Desert of the San Luis Valley, Colorado. Water, Air, and Soil Pollution, 205(1-4): 289304.

36. Mix, K., V. Lopes, and W. Rast. 2011. Annual and growing season temperature changes in the San Luis Valley, Colorado. Water Air Soil Pollut. 220(1): 189-203.

37. North, D. 1990. Institutions, Institutional Change, and Economic Performance. Cambridge: Cambridge University Press.

38. Ostrom, E. 1990. Governing the Commons: The Evolution of Institutions for Collective Action. New York, NY: Cambridge University Press.

39. Ostrom, E. 1992. Crafting Institutions for User-governing Irrigation Systems. San Francisco, CA: Institute of Contemporary Studies.

40. Ostrom E. 2005. Understanding Institutional Diversity. Princeton, NJ: Princeton University Press.

41. Pérez, I., Janssen, M.A., Anderies, J.M. 2016. Food Security in the Face of Climate Change: Adaptive Capacity of Small-Scale Social-Ecological Systems to Environmental Variability. Global Environmental Change 40: 82-91.

42. Poteete, A. R., M. A. Janssen, and E. Ostrom. 2010. Working together: Collective action, the commons, and multiple methods in practice. Princeton, NJ: Princeton University Press.

43. Sabatier, P. 2007. Theories of the Policy Process, Second Edition. Cambridge, MA: Westview Press.

44. Smith, S.M. 2016. Common Property Resources and New Entrants: Uncovering the Bias and Effects of New Users. Journal of the Association of Environmental and Resource Economists 3(1): 1-36.

45. Torell, G. L., \& Ward, F. A. 2010. Improved Water Institutions for Food Security and Rural Livelihoods in Afghanistan's Balkh River Basin. International Journal of Water Resources Development, 26(4), 613-637.

46. Turral, H., Malano, H., \& Chien, N. V. 2002. Development and specification of a service agreement and operational rules for La Khe irrigation system, Ha Dong, Vietnam. Irrigation and Drainage, 51(2), 129-140.

47. Ward, F. A., Amer, S. A., \& Ziaee, F. 2013. Water allocation rules in Afghanistan for improved food security. Food Security, 5(1), 35-53.

48. Wilson, D., Ostrom, E., \& Cox, M. 2013. Generalizing the core design principles for the efficacy of groups. Journal of Economic Behavior \& Organization, 90: S21-S32.

49. Yu, H., Edmunds, M., Lora-Wainwright, A., \& Thomas, D. 2016. Governance of the irrigation commons under integrated water resources management - A comparative study in contemporary rural China. Environmental Science and Policy, 55: 65-74.

50. Zwart, W., \& Leclert, L. 2010. A remote sensing-based irrigation performance assessment: a case study of the Office du Niger in Mali. Irrigation Science, 28(5): 371 385.

\section{Sub-Appendix A. Survey Questions and Available Responses Used in Analysis}

6. Is your water use association incorporated? 
Yes

No

In Process

10. What is the current size of your association as measured in:

Acres

Members

18. Does your association have access to a surface reservoir?

Yes

No

29. Please mark whether the amount of water a member in your association can use is proportional to any of the following:

The amount of land users own

The amount of water users have contributed

The amount of labor users are required to contribute

The amount of financial contributions users are required to make

Shares owned

Not proportional to anything

Other

32. Within your association, is water normally distributed by turns along a rotation, or to everyone at once in proportion to their rights?

Rotational

Proportional

Explanation

33. Does this change when you have less than full flow?

Yes

No

Explanation

34. How is compliance with water use rules monitored and enforced (check all that apply)?

No monitoring

Self-monitored by association members

Monitored by members

Monitored by Mayor Domo

Monitored by ditch rider

Monitored by water commissioner 
Monitored by others

Monetary sanctions

Water use is cut off

Expulsion from scheme

Other sanctions

No sanctions

38. Do any formal or informal agreements among members of your association involve changing water allocations between them in times of drought and water scarcity?

Yes, Formal

Yes, Informal

No

39. What process, if any, exists for members to exchange water or land within your association?

\section{OPEN ENDED RESPONSE}

41. Please describe any scarcity arrangements, how frequently they are invoked, and any changes to irrigation or cultivation practices required during scarcity:

\section{OPEN ENDED RESPONSE}

53. For each threat identified, evaluate the extent to which that threat is problematic for your association, rating this from $1-5(5=$ very problematic, $1=$ not problematic $)$

Poor quality infrastructure (1-5)

Poor quality soils (1-5) 